\title{
LAS LUCERNAS REPUBLICANAS DE LUCENTUM (TOSSAL DE MANISES, ALACANT)
}

\author{
REPUBLICAN OIL LAMPS IN LUCENTUM (TOSSAL DE MANISES, ALICANTE)
}

ANNA GARCIA BARRACHINA

Museo Arqueológico de Alicante (MARQ)

\section{Resumen}

Presentamos en este artículo las lucernas de tipología republicana procedentes de la ciudad romana de Lucentum. Las lucernas se presentan enmarcadas tipológicamente y se proporciona su datación según su contexto estratigráfico, se recopilan además las marcas existentes sobre ellas y los motivos decorativos que presentan.

Palabras clave. Lucernas republicanas, Lucentum, contexto estratigráfico.

\section{Abstract}

In this paper we present the oil lamps from the Republican period discovered in the Roman city of Lucentum. These oil lamps follow a typological order and their dating is provided according to their stratigraphic context. Their marks and decorative motifs are also lsited.

Key words. Republican oil lamps, Lucentum, stratigraphic context.

Para citar este artículo / To cite this article: Garcia Barrachina, A. M. (2016). Las lucernas republicanas de Lucentum (Tossal de Manises, Alacant) Lucentum, XXXV, 117-140. doi: 10.14198/LVCENTVM2016.35.06

Para enlazar con este artículo / To link to this article:

http://dx.doi.org/10.14198/LVCENTVM2016.35.06 


\title{
LAS LUCERNAS REPUBLICANAS DE LUCENTUM (TOSSAL DE MANISES, ALACANT)
}

\author{
REPUBLICAN OIL LAMPS IN LUCENTUM (TOSSAL DE MANISES, ALICANTE)
}

\author{
ANNA GARCIA BARRACHINA \\ Museo Arqueológico de Alicante (MARQ)
}

\section{INTRODUCCIÓN}

La ciudad romana de Lucentum está emplazada en el promontorio conocido como Tossal de Manises, yacimiento situado en el barrio de l'Albufereta, a unos 3,5 kilómetros al norte del núcleo urbano de Alicante.

Aunque no podemos descartar con rotundidad la existencia de un asentamiento previo, en ninguna de las intervenciones recientes se han localizado niveles anteriores al siglo III a.C. Los materiales de los siglos V/IV a.C. se detectan en los rellenos de la primera muralla y en las regularizaciones del interior del enclave y serían fruto del transporte desde otros puntos cercanos (Olcina, Guilabert y Tendero, 2014, 202). La primera gran fase constructiva se data en el último tercio del siglo III a.C. construyéndose una potente fortificación que delimitará el asentamiento, una primera trama urbana y cisternas de tipología púnica. La construcción de este espacio urbanizado, de marcado carácter militar, se asocia con la consolidación territorial cartaginesa instaurada con la conquista bárquida de Iberia dentro del plan de ordenación y control efectivo de sus posesiones peninsulares (Olcina, Guilabert y Tendero, 2014, 202). El fin de esta fase urbana ofrece un marco cronológico que permite defender su destrucción, con potentes estratos de incendio, hacia el año 209 a.C., año en que Escipión conquista la cercana capital bárquida (Olcina, Guilabert y Tendero, 2014, 204).

Después de la destrucción, asistimos a un largo periodo de abandono del yacimiento, solo frecuentado esporádicamente. No se han localizado contextos de habitación para el siglo II a.C. Este abandono será el

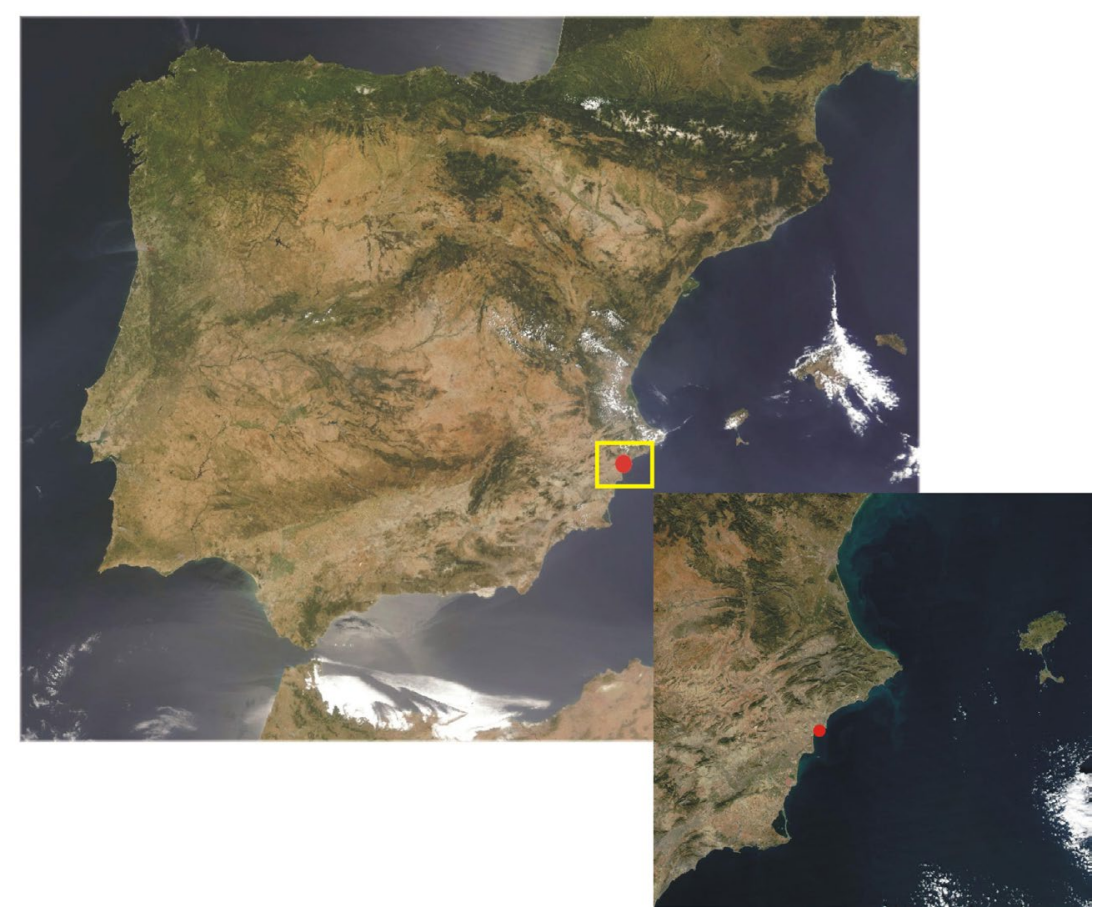

Figura 1: Situación de Lucentum en la Península Ibérica. 
causante de la falta de continuidad de la trama urbanística de época bárquida en la posterior ciudad romana ya que el nuevo viario que se trazará no coincidirá con el primigenio, derivado de la destrucción ya comentada, del vacío poblacional del siglo II a.C. y de la función del yacimiento durante el siglo I a.C., provocando estos hechos una ruptura urbana (Olcina, Guilabert y Tendero, 2014, 204).

A finales del primer cuarto del siglo I a.C. se detecta una nueva ocupación extensiva que se reflejará en especial en la reconstrucción completa de sus defensas que seguirán la forma definida en la primera fortificación. El trazado murario se complementa con dos elementos defensivos que nos hablarían de un establecimiento militar relacionado con las Guerras Sertorianas. Esta refortificación no se corresponde con la urbanización al interior del enclave donde únicamente se detectan estructuras de poca importancia, aisladas y combinadas con espacios abiertos que no definen ninguna trama urbana (Olcina, Guilabert y Tendero, 2014, 205).

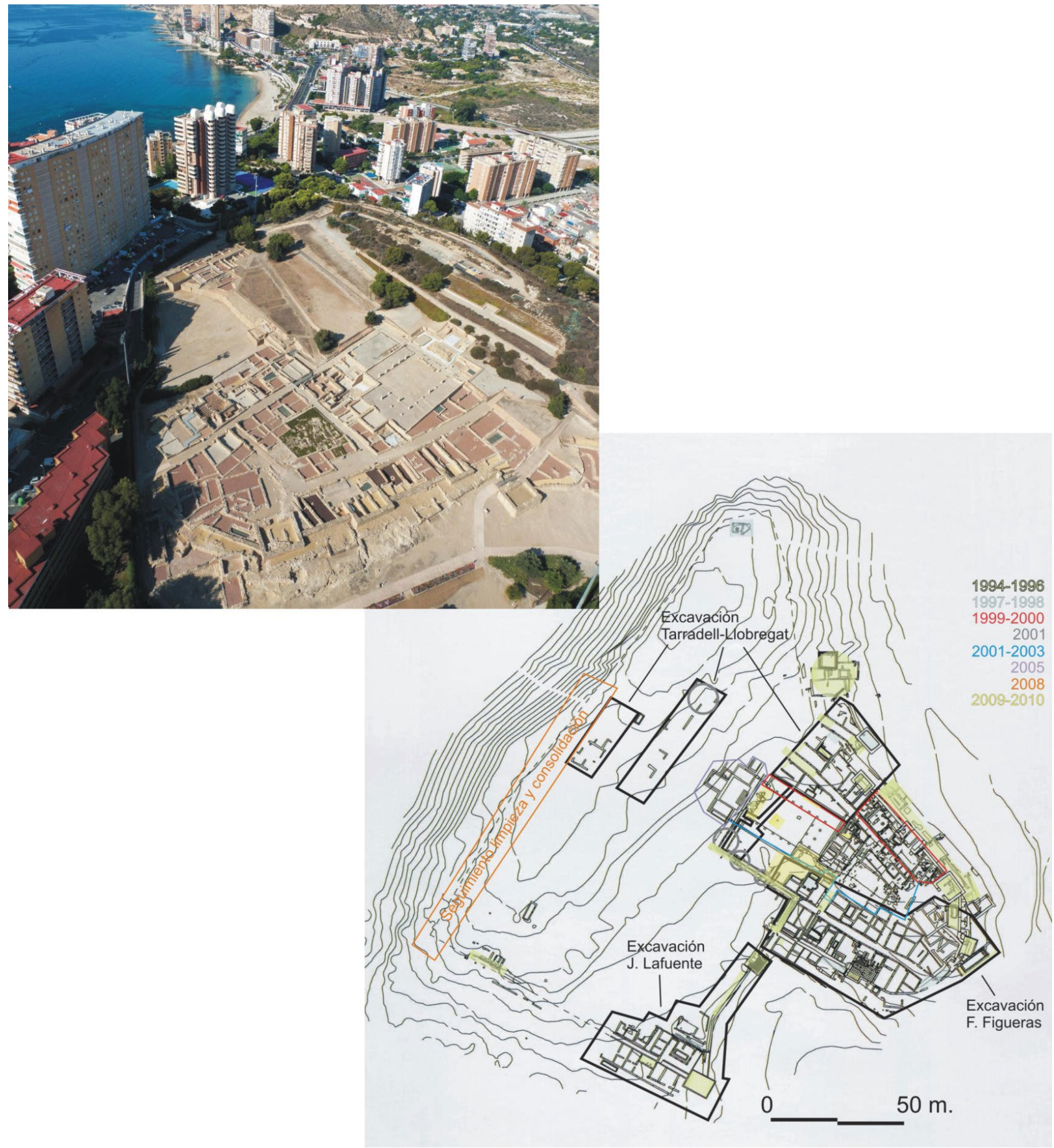

Figura 2: Vista aérea del yacimiento de Lucentum y planta con las zonas excavadas de las que proceden las lucernas. 
Una de las pruebas más importantes de la fundación del municipio es la construcción del primer foro municipal, datado entre el 30 y el 20 a.C., al inicio del mandato de Augusto. Se trata del germen a partir del cual se articulará el municipio de Lucentum. En las dos últimas décadas del siglo I a.C. se registra una intensa actividad constructiva pues intramuros se trazan nuevas calles. El emperador Augusto le otorgó el estatuto jurídico de municipio así que, en el margen temporal que nos ocupa, el yacimiento muestra una importante transformación urbana y monumental (Olcina, 2009, 38-52; Olcina, Guilabert y Tendero, 2014, 206-207). A lo largo del gobierno de Tiberio se establece definitivamente la morfología urbana de Lucentum.

\section{PROCEDENCIA DE LOS MATERIALES}

Parte de las lucernas están descontextualizadas ya que proceden de excavaciones sin metodología arqueológica practicadas desde finales del siglo XVIII. Serán los materiales procedentes de las campañas realizadas a partir de la década de los 90 del siglo XX, es decir las que cuentan con registro arqueológico, los que nos servirán a la hora de intentar establecer una cronología de cada tipo en Lucentum.

A continuación del apartado relativo a las decoraciones se expone una clasificación ejemplar por ejemplar con la unidad estratigráfica de la que proceden y con los materiales significativos que conforman dicha unidad.

\section{METODOLOGÍA Y ESTRUCTURACIÓN DEL ESTUDIO}

Las tipologías que hemos utilizado principalmente para la clasificación de las lucernas republicanas han sido las elaboradas por Ricci (1973, 168-234) y Dressel (1899), para clasificar los materiales también se ha seguido a Bussière (1995).

Por lo que respecta a estadística, contabilización de fragmentos y cantidades totales el sistema de cuantificación que hemos seguido es el del recuento del número total de fragmentos (NFR) que en el caso concreto de las lucernas, coincide con el sistema de recuento conocido como Número Máximo de Individuos $(\mathrm{NMxI})$ que considera cada fragmento como un individuo cerámico.

Las lucernas se presentan ordenadas tipológicamente, aportándose la cronología de las unidades estratigráficas correspondientes al periodo republicano que han sido publicadas y estudiadas con profundidad, la cronología de ellas está ajustada estratigráficamente y con respecto a los materiales que las componen. De igual modo se aportarán paralelos bibliográficos de ejemplares con estratigrafía ya que pensamos que no tiene sentido aportar largos listados de piezas descontextualizadas que no proporcionan más información.
El número máximo de individuos localizados hasta este momento es de 1631, sumando los procedentes del fondo museo y los de excavaciones con metodología arqueológica, y se reparten de la siguiente forma:

\section{Total lucernas de Lucentum}

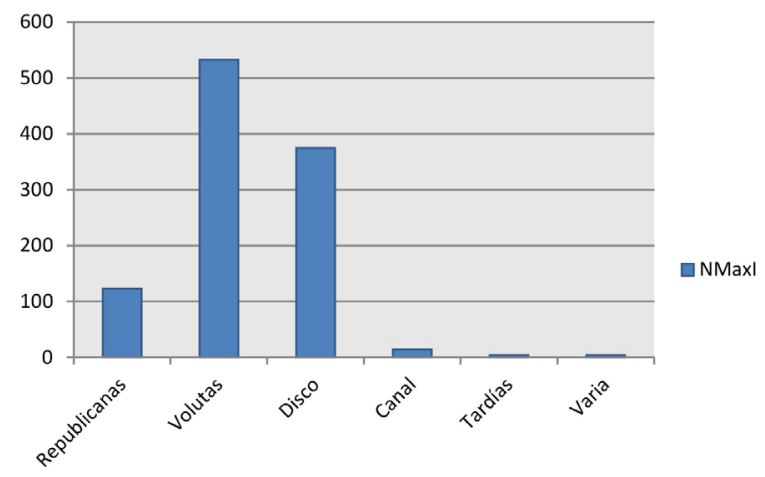

Figura 3: Gráfica con el total de lucernas de Lucentum.

En la figura 3 se observan las cantidades de cada grupo lucernario, el grupo de volutas lo componen 533 ejemplares, el de disco 375 ejemplares, el de canal 14 piezas mientras que el grupo de las tardías y el de $v a$ ria apenas está representado. El grupo de las lucernas republicanas está compuesto por 123 ejemplares, lo que supone un 7,5\% del total localizado hasta la fecha, distribuidos tipológicamente tal y como podemos ver a continuación:

\section{Total lucernas republicanas}

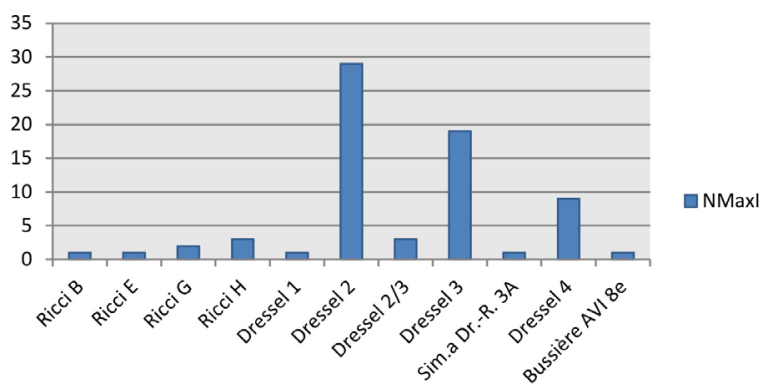

Figura 4: Total lucernas republicanas.

En la gráfica de la figura 4 vemos que los ejemplares más antiguos (Ricci B, E, G y H) apenas están representados, en cambio destaca el aumento en número de ejemplares del tipo Dressel 2. Los tipos Dressel 3 y Dressel 4 están representados en menor medida. En el caso concreto de la Dressel 4, puede deberse a que ya han hecho acto de presencia las lucernas de volutas Dressel 9 A.

Si dentro de las lucernas republicanas separamos las procedentes del fondo museo y las de excavaciones con contexto vemos que las gráficas quedan del siguiente modo: 
Lucernas republicanas de excavaciones anteriores a 1990

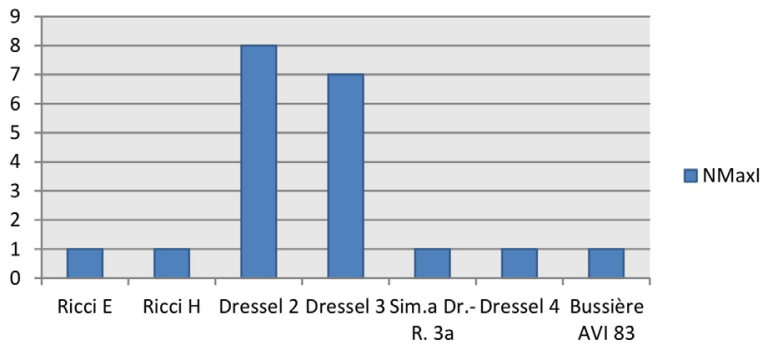

Figura 5: Lucernas republicanas procedentes de excavaciones sin metodología arqueológica.

\section{Lucernas republicanas con estratigrafía}

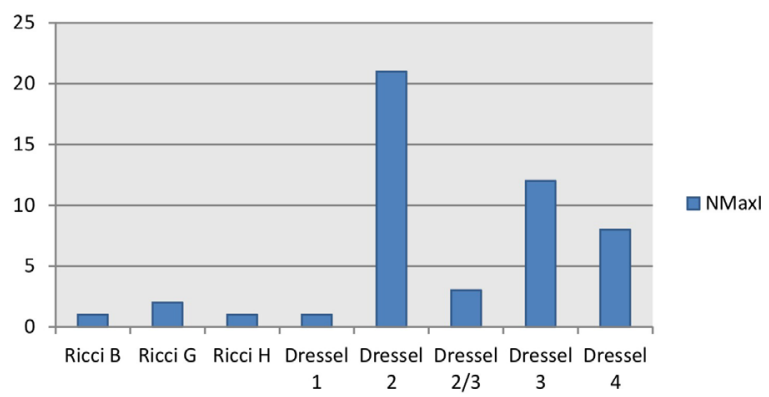

Figura 6: Lucernas republicanas procedentes de excavaciones con metodología arqueológica.

Tras observar las gráficas de las figuras 5 y 6 se aprecia el destacado aumento en la presencia de ejemplares Dressel 2 y Dressel 3, predominando siempre la Dressel 2. En el apartado correspondiente a cada tipo analizaremos sus cronologías en Lucentum. También se observan ciertas diferencias como la mayor o menor presencia de las lucernas Dressel 4 según se trate de excavaciones antiguas o recientes, no sabemos si puede deberse o no a las distintas áreas excavadas. Este será un estudio que abordaremos en un futuro, cuando incluyamos la totalidad de lucernas del yacimiento.

\section{RICCI B}

Es una lucerna de cuerpo troncocónico con un apéndice lateral y rostrum alargado. Está producida a torno.

En el Tossal contamos con un ejemplar (CS. 16769/ TM94-20-054) procedente de la UE 20013, cuya cronología se ha fijado entre el 130 y el 70 a.C. (Fig. 7, $\left.\mathrm{n}^{\mathrm{o}} 1\right)$.

Las lucernas Ricci B en origen procederían de Italia Central y Campania, son ejemplares que presentan un recubrimiento de barniz negro (Morillo, 2015, 344) aunque en el ejemplar de Lucentum no se aprecian restos de engobe.

En Numancia se conoce un ejemplar (Romero, 1990, 266-267) correspondiente al Campamento III de Renieblas, de mediados del s. II a.C.

\section{RICCI E}

El cuerpo es troncocónico y el disco, que es circular, está delimitado por una moldura en relieve. Presenta un asa en forma de anillo. Tiene pie y el pico presenta forma de yunque.

En Lucentum está documentada en una ocasión y sin contexto (TM-40, B, estrato 3, 1958), (Fig. 7, $\mathrm{n}^{\circ}$ 2).

Este tipo de lucerna, al igual que hemos comentado para Ricci B, sería elaborado originariamente en la zona de la Italia central y Campania. Según Huguet y Ribera $(2013,210)$ sus características técnicas indicarían que las piezas procederían de los talleres napolitanos que fabricaban vajilla Campaniense A.

Procedentes de Numancia se documentan cuatro ejemplares del tipo Ricci E (Romero, 1990, 259-262, fig. 1) fechados tres de ellos en 134-133 a.C. Para el cuarto ejemplar se desconoce la procedencia exacta.

\section{RICCI G}

Es una lucerna fabricada a molde, con un disco de reducidas dimensiones y decoración radial en la parte superior, el rostrum presenta forma de yunque.

En el Tossal de Manises se documenta en dos ocasiones (Fig. 7, n 3 y n $^{\circ} 4$ ), en ambas presenta una pasta de color gris y el barniz, negro y brillante, está muy perdido.

Una de ellas (CS. 14103/TM99-FO-1625), (Fig. $\left.7, n^{\circ} 3\right)$, está fechada estratigráficamente (UE 1067) a partir de la última década del siglo I a.C. hasta inicios del reinado de Tiberio (Guilabert et alii, 2010). En la base presenta una marca incompleta e ilegible que viene referida en el apartado dedicado a las marcas.

Este tipo de lucerna fue fabricada en talleres del sur de Italia y Roma (Ricci, 1973, 222-223; Morillo, 2015, $345)$ y en Hispania se ha localizado un taller que las producía en Corduba, con una cronología comprendida entre el 135-30 a.C. (Moreno, 1991, 193-198).

Paralelos con estratigrafía para el tipo Ricci G se encuentran en Valentia con una cronología de circa 75 a.C. (Ribera y Marín, 2004-05, 274). En Baetulo se datan por el contexto durante la $1^{\mathrm{a}}$ mitad del s. I d.C. y el s. II d.C. (Celis, 2008, 238 y 243). En el pecio de Escombreras 2 en la $1^{a}$ mitad del s. I a.C. (AA. VV., 2004, 209). En Tarraco en un contexto del 200 al 175 a.C. (Díaz, 2000, 225). En la Casa Pastors de Gerunda aparece con una cronología de la $3^{\text {a }}$ década del siglo I a.C. (Nolla, 1999, 191).

\section{RICCI H}

Se caracterizan por tener un cuerpo cilíndrico y alto, gran orificio de alimentación y base plana. Se fabrica a torno y no se barniza.

Está documentada en tres ocasiones (CS. 3106, CS. 2648 y TM01-BC-2327), (Fig. 7, no 5, no 6 y n ${ }^{\circ} 7$ ), de las que la tercera procede de excavaciones con contexto 


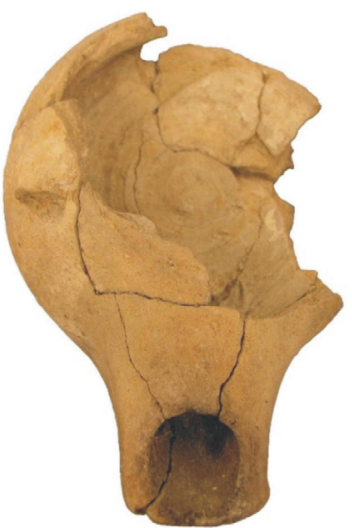

1

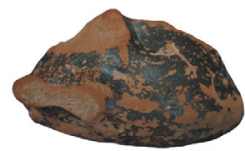

2

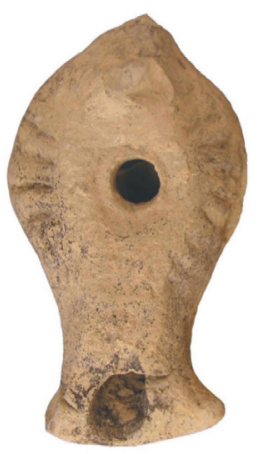

3

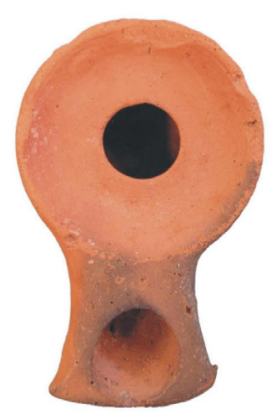

5

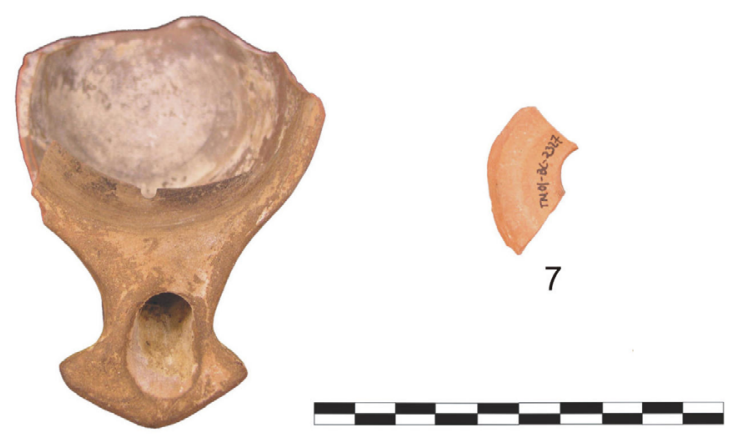

6

Figura 7: Ricci B ( $\left.n^{\circ} 1\right)$, Ricci E (n $n^{\circ}$ ), Ricci G ( $n^{\circ} 3$ y 4), Ricci H (n ${ }^{\circ} 5,6$ y 7), Dressel $1\left(n^{\circ} 8\right)$.

(UE 3056) cuya cronología se ha fijado desde el 40/30 a.C. hasta el cambio de Era. Las otras dos proceden de los fondos del museo, sin contexto arqueológico.

Lucernas de este tipo fueron fabricadas en la Italia central (Ricci, 1973, 222-226).

\section{DRESSEL 1}

Es una lucerna que presenta decoración radial en la parte superior del cuerpo. Está hecha a molde y la arcilla suele ser de color gris.

En Lucentum está documentada en una ocasión (TM00-SB-5549 y TM00-SB-5369), (Fig. 7, n 8), procedente de las UUEE 2389 y 2392 que le otorgan una cronología de época tardorrepublicana o inicios del mandato de Augusto.
Hemos encontrado paralelos con estratigrafía en Tarraco en contextos del 150-125 a.C. y del 125-100 a.C. (Díaz, 2000, 235 y 240).

En Cosa (Italia) se documentan en diversos contextos, del 150 al 125 a.C., del 150 al 70 a.C. y, por último, del 125 a.C. al 50 d.C. (Rickman y Wynick, 1994, 47-49).

Con sólo un ejemplar no nos es posible fijar una cronología para dicha lucerna en Lucentum.

\section{DRESSEL 2}

Lucerna de cuerpo bicónico con una aleta lateral, presenta el pico en forma de yunque. Su rasgo diferenciador es que el cuerpo presenta pequeñas esferas en relieve aunque, en ocasiones, también se documenta 

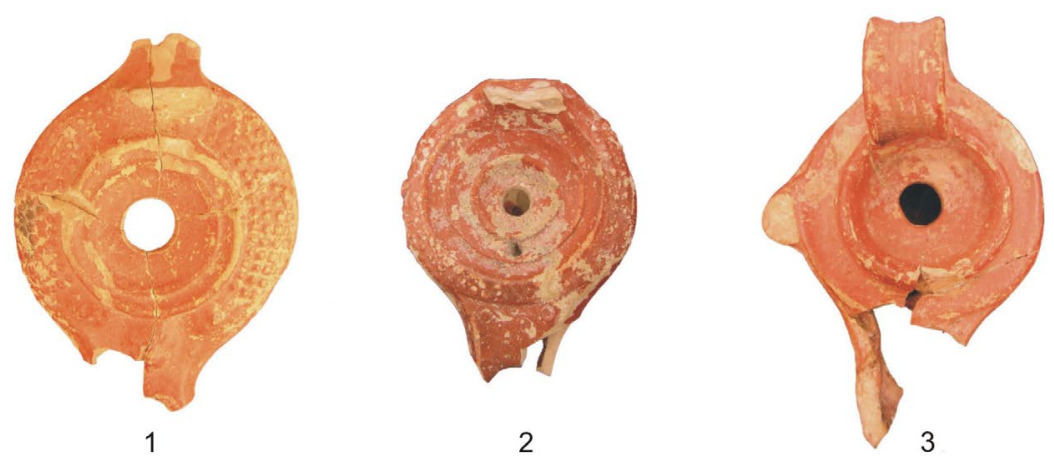

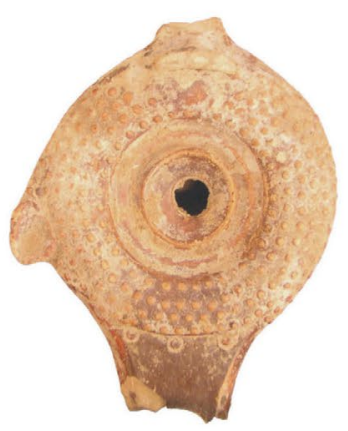

4

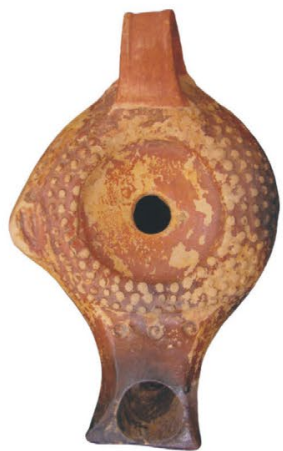

5

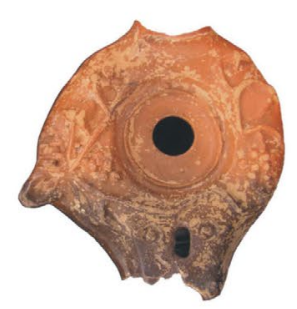

6

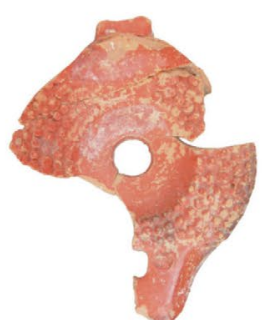

7

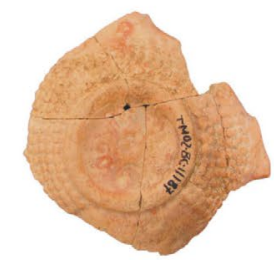

8

Figura 8: Dressel 2.

decoración vegetal a base de pámpanos, sarmientos y racimos de uva (Fig. 8, n 6; Fig. 9, n ${ }^{\circ}$ 3).

En el Tossal de Manises está representado por 29 ejemplares (Figs. 8, 9 y 10) de los que 18 tienen contexto estratigráfico. Las pastas son depuradas y van del color beige al beige-rosado, los barnices son de color marrón, negro con irisaciones metálicas, marrón-anaranjado, predominando el de color rojo-anaranjado. Según Pavolini $(1987,145)$ es hacia el 50-30 a.C. cuando se pasa de producir el barniz de color negro al de tonos anaranjados.

Esta forma fue producida en origen en los talleres centroitálicos de los alrededores de Roma (Ricci, 1974). En las excavaciones desarrolladas en la ciudad romanorrepublicana de La Cabañeta (El Burgo de Ebro, Zaragoza) se han recuperado tres moldes de los que uno sirvió para fabricar lucernas del tipo Dressel 2. Los negativos proceden del relleno de un depósito colmatado hacia los años 90-80 a.C. con lo cual el uso de los moldes sería anterior, a partir de inicios del siglo I a.C. y hasta las Guerras Sertorianas (Mínguez y Mayayo, 2014, 151-164).

Desconocemos el lugar de fabricación de los ejemplares de Lucentum.

Los ejemplares con cronología estratigráfica se agrupan de la siguiente manera:

- 40/30 a.C. - fines s. I a.C.: un ejemplar (TM01BC-16172 y 16173, UUEE 3441 y 3433), (Fig. 8, $\left.\mathrm{n}^{\mathrm{o}} 2\right)$.

- 40/30 a.C. - cambio de Era: un ejemplar (TM01BC-4405, UE 3512), (Fig. 10, no 4).

- 40/30 a.C. - 40 d.C.: un ejemplar (TM02BC-12513, UE 3921), (Fig. 9, no 2).

- 40/30 a.C. -50 d.C.: un ejemplar (TM01-BC-8639, UE 3696), (Fig. 9, nº 6). 


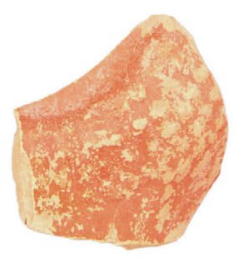

1

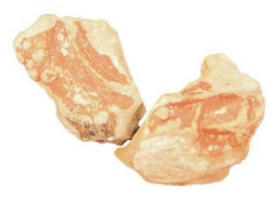

3

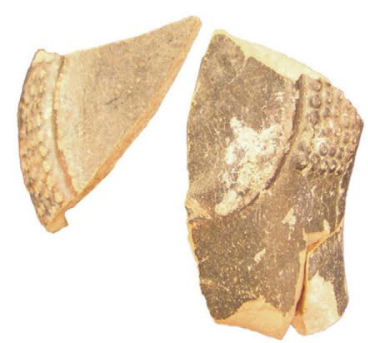

5

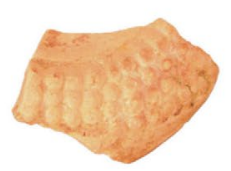

7
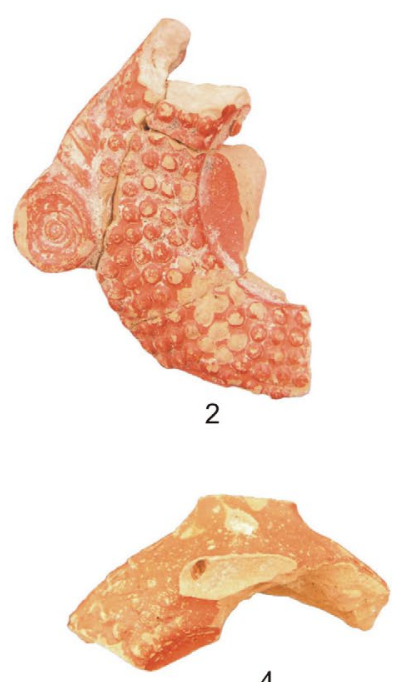

4

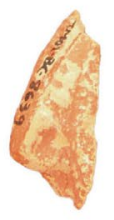

6

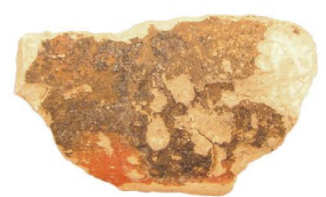

8

Figura 9: Dressel 2.

- 30 a.C.-15 a.C.: dos ejemplares (TM09-FO-14762, UE 5854 y TM09-FO-14100, UE 5861), (Fig. 10, $\left.\mathrm{n}^{\circ} 9 \mathrm{y} \mathrm{n}^{\circ} 12\right)$.

- 50-65 d.C.: tres ejemplares (TM01-BC-3370, UE 3414, TM02-BC-11958 у TM02-BC-10884, UUEE 3846), (Fig. 9, $\mathrm{n}^{\circ} 4 \mathrm{y} \mathrm{n}^{\circ}$ 8; Fig. 10, $\mathrm{n}^{\circ} 2$ ).

- 30/50 d.C. $-1^{\mathrm{a}}$ m. s. II.: un ejemplar (TM02BC-11187, 11133 y 10672, UUEE 3863 у 3844), (Fig. 8, $\mathrm{n}^{\mathrm{o}} 8$ ).

- 50 - 65 d.C.: tres ejemplares (TM02-BC-14134, UE 3977, TM02-BC-14171y TM02-BC-14172, UE 3982), (Fig. 10, no 1, no 6 y n $^{\circ} 5$ ).

- Inicios época Flavia: un ejemplar (TM98/T-VI/349, UE 1036), (Fig. 10, $n^{\circ} 8$ ).

- Cronología Flavia: un ejemplar (TM98/T-VI/216, UE 1040), (Fig. 9, n 1).

- 100 - 150 d.C.: un ejemplar (TM05-FO-12620, UE 5397), (Fig. 9, nº 3).
- $100-230$ d.C.: un ejemplar (TM05-FO-10688, UE 5133), (Fig. 9, n 5).

- $2^{\mathrm{a}} \mathrm{m}$. s. II - primer $1 / 3$ s. III d.C.: un ejemplar (TM02-BC-14642, UE 3771), (Fig. 10, nº 3).

Tras analizar la cronología de este tipo concreto en $L u$ centum, proporcionada por el contexto estratigráfico, parece observarse que arranca o se documenta a partir de la década 40/30 a.C., con anterioridad no se tiene constancia, al menos hasta la fecha.

Algunos de estos ejemplares presentan alguna marca, básicamente se trata de letras de gran tamaño rodeadas de puntos o una marca formada por cinco puntos. Se desarrollan en el apartado referido a ellas.

Se encuentran paralelos con estratigrafía en las siguientes excavaciones:

En Valentia se documenta un ejemplar (Lerma, 1988, 31) con marca rehundida en la base consistente 


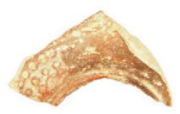

1

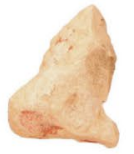

4

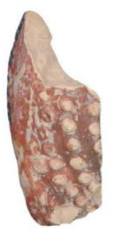

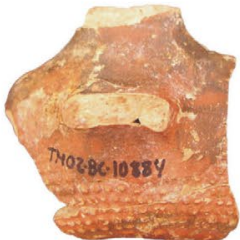

2
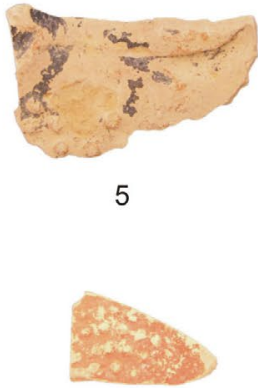

8

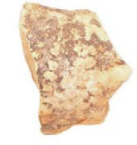

3

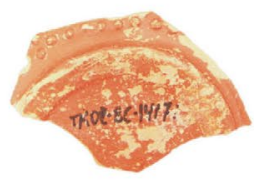

6

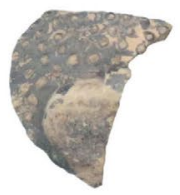

9

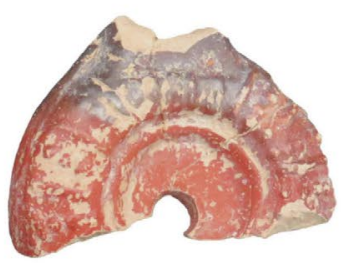

10

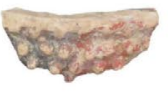

12

13

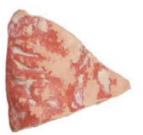

11

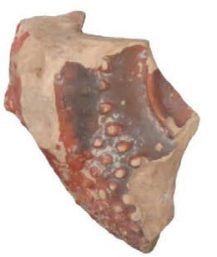

Figura 10: Dressel 2.

en una R con cuatro puntos alrededor (Martín 1962, 94-95), marca muy similar a las localizadas en Lucentum y que más adelante explicaremos.

En Ampurias a mediados del siglo I a.C. y también en el cambio de Era (Aquilué et alii, 2008, 39 y 44).

En Baetulo se documentan desde el 50/30 a.C. hasta el siglo II d.C. (Celis, 2008, 184).

Ribera y Marín $(2004-05,274)$ proponen para $\mathrm{Va}$ lentia una cronología de circa 75 a.C.

En Tarraco se documentan en un contexto del 10075 a.C. (Díaz, 2000, 245).

En la villa romana dels Tolegassos un fragmento procede de un conjunto datado a finales del s. II o muy a principios del s. I a.C. (Casas y Rocas, 1989, 86).

En Cosa (Italia) aparecen en los siguientes contextos: seis ejemplares se fechan entre el 175 y el 70 a.C.,
12 ejemplares del 150 al 70 a.C., cuatro ejemplares del 120 al 20 a.C., 12 ejemplares del 25/20 a.C. al 50 d.C., 15 ejemplares del 50 al circa 100 d.C., tres ejemplares del 100 al 225 d.C. (Rickman y Wynick, 1994, 55-64).

\section{DRESSEL $2 / 3$}

Presenta aletas laterales y decoración a base de glóbulos o perlas en relieve. Es una forma de transición entre la Dressel 2 y la Dressel 3, los talleres de producción serían los mismos.

En Lucentum se documenta en tres ocasiones (TM05-FO-6744, TM01-BC-5542 у TM99-SB-2416), (Fig. 13, $\mathrm{n}^{\mathrm{o}} 1 \mathrm{a} \mathrm{n}^{\mathrm{o}} 3$ ), todas procedentes de excavaciones 


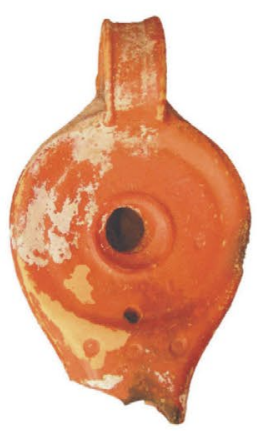

1

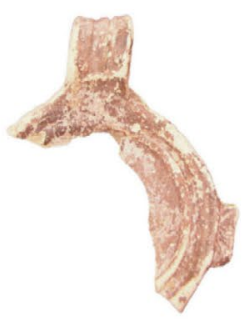

4

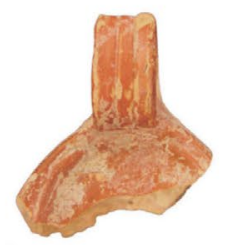

8
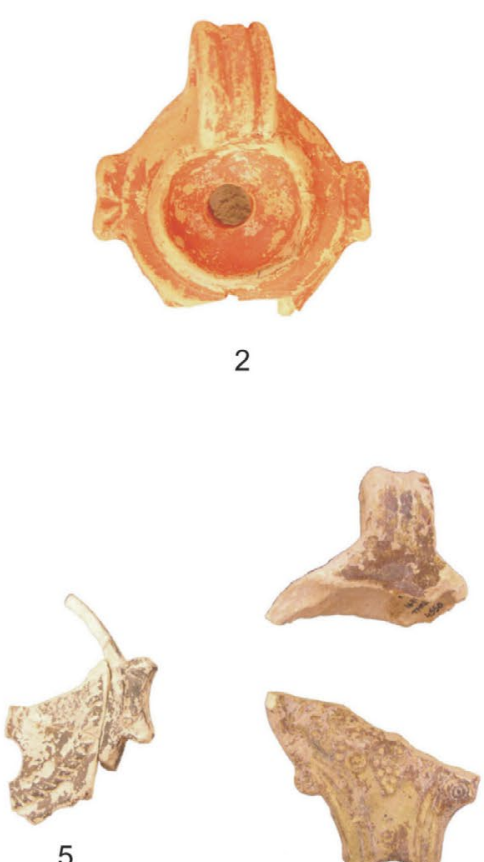

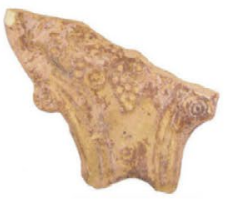

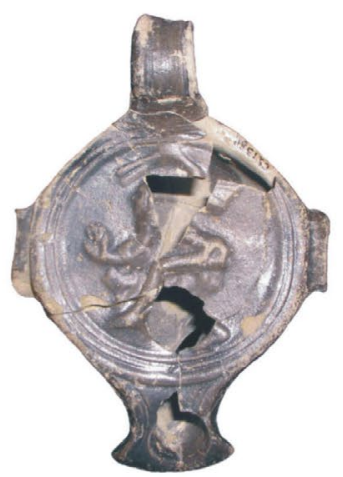

3

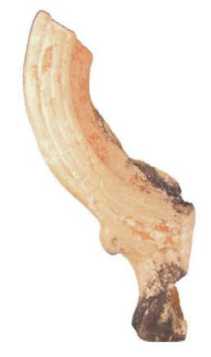

7

6

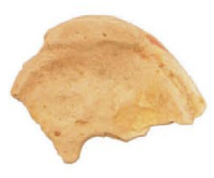

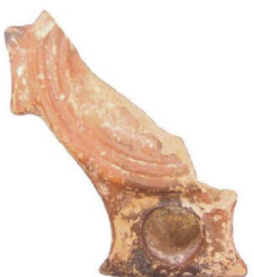

10

Figura 11: Dressel 3. La pieza $n^{\circ} 1$ podría considerarse una variante y las $n^{\circ} 6$ y 7 serían similares a Dressel-Ricci 3 a.

con estratigrafía arqueológica, la primera es posterior a la necrópolis islámica, la segunda se fecha del 50 al 65 d.C. y la tercera del 220 al 50 a.C. Las pastas oscilan del color beige al color anaranjado. El engobe es rojo-anaranjado.

- 220-50 a.C.: un ejemplar (TM99-SB-2416, UE 2046), (Fig. 13, no 3).

- 50-65 d.C.: un ejemplar (TM01-BC-5542, UE 3061), (Fig. 13, n 2 ).

- Post maqbara islámica: un ejemplar (TM05FO-6744, UE 4506), (Fig. 13, nº 1).

En Tarraco, Díaz García (2000, 245) publica un contexto del 100 al 75 a.C.

En Badalona, Celis Betriu documenta un ejemplar en un estrato de época Flavia y cita a Ricci cuya cronología propuesta para este tipo era del siglo I a.C. (Celis, 2008, 184).

\section{DRESSEL 3}

Presenta aletas simétricas laterales decoradas a base de hojas y gotas, el pico tiene forma de yunque. Se trata de la primera lucerna romana con decoración en el disco.

Al igual que la Dressel 2, fue producida en los talleres centroitálicos del entorno de Roma (Ricci, 1974).

Contamos con un total de 19 ejemplares de los que 12 proceden de excavaciones con contexto arqueológico. Las pastas predominantes son las de color beige o las de color gris, un único ejemplar 


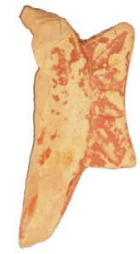

1
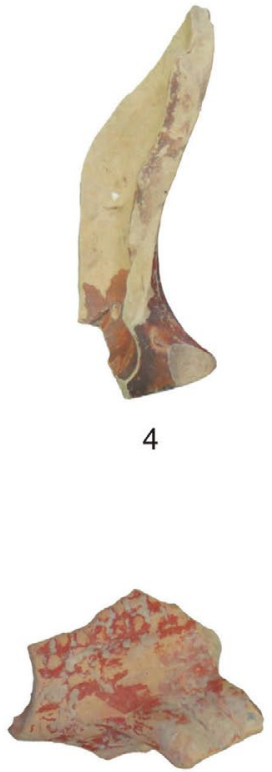

7

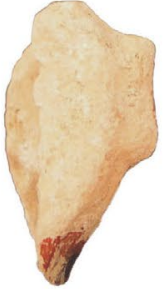

2

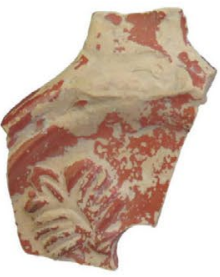

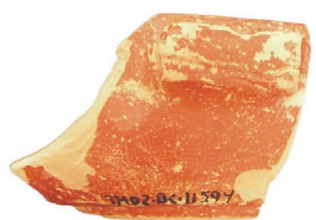

3
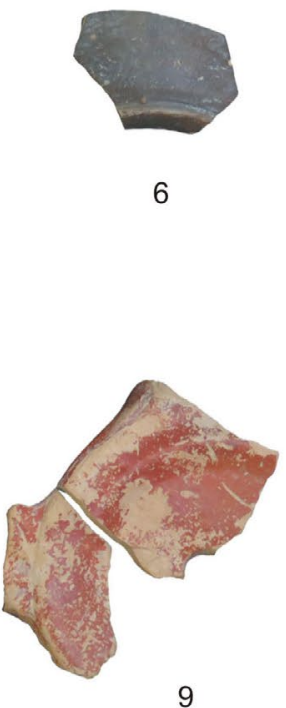

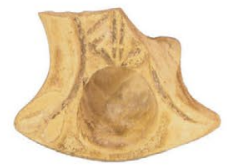

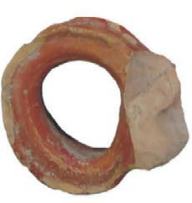

8

10

Figura 12: Dressel 3.

presenta pasta amarillo-verdosa. Los barnices son grises, marrones y rojo-anaranjados, predominando estos últimos.

En este tipo incluimos piezas que podrían ser una variante o similares, entre ellas se encuentran tres piezas (TM02-BC-11997, TM-6523/CS. 2627 y TM67-1139), (Fig. 11, no 9, $\mathrm{n}^{\circ} 1$ y n $^{\circ} 8$ ) que podrían considerarse como una variante de la Dressel 3 , aunque también se pueden clasificar como Palol 2B y similar a Leibundgut II. Se incluye además una Dressel-Ricci 3 A (TM02-FO-4550/CS. 16744), (Fig. $\left.11, \mathrm{n}^{\circ} 6\right)$ y un ejemplar que parece de transición entre las lucernas republicanas y las de volutas y que presenta el extremo de una hoja en el canal creado entre las volutas (TM02-BC-11117, UE 3859), (Fig. $\left.12, \mathrm{n}^{\mathrm{o}} 10\right)$.

Por cronologías estratigráficas se agrupan de la siguiente manera:
- 40/30 a.C. - cambio de Era: un ejemplar (TM01BC-4427, UE 3512), (Fig. 12, $n^{\circ} 2$ ).

- 15/10 a.C. - primeros años del reinado de Tiberio: 1 ejemplar (TM02-BC-11593/CS. 13811, UE 3871), (Fig. 11, no 3 ).

- Claudio-Nerón para la variante Palol 2B: un ejemplar (TM02-BC-10843, UE 3846), (Fig. 11, nº 10).

- 50-65 d.C.: un ejemplar (TM02-BC-11997, UE 3846), (Fig. 11, no 9).

- 30-50 d.C.: dos ejemplares (TM02-BC-11188 y 11188b, UE 3863), (Fig. 12, $\mathrm{n}^{\circ} 1 \mathrm{y} \mathrm{n}^{\mathrm{o}} 8$ ).

- $1^{\mathrm{a}}$ m. s. II: un ejemplar (TM02-BC-11117, UE 3859), (Fig. 12, $\mathrm{n}^{\mathrm{o}} 10$ ).

- $2^{\mathrm{a}} \mathrm{m}$. s. II - primer $1 / 3 \mathrm{~s}$. III d.C.: dos ejemplares (TM01-BC-1576, UE 3157 у TM02-BC-13535, UE 3766), (Fig. 11, no 4 y no 5).

- $230-280$ d.C.: un ejemplar (TM09-FO-13459, UE 5738), (Fig. 12, no 7). 
- 231 - 300 para el ejemplar de Dr.-Ricci 3 A: 1 ejemplar (TM02-FO-4550/CS. 16744, UE 1675), (Fig. 11, $\mathrm{n}^{\mathrm{o}}$ 6).

- 100-600 d.C.: un ejemplar (TM10-CTP-1164 y TM10-CTP-2281, UE 7081 y 7106), (Fig. 12, nº 9).

Tras observar las cronologías de las lucernas Dressel 3 en Lucentum, parece que se repite la misma situación que hemos visto con el tipo Dressel 2, su cronología en el yacimiento que nos ocupa se inicia a partir del 40/30 a.C. Son, por tanto, ambas formas coincidentes en cuanto a cronología se refiere.

Destaca un ejemplar (TM02-BC-11593/CS. 13811), (Fig. 11, no 3) que presenta decoración en el disco formada por un bailarín con dos bastones. Este ejemplar procede de la UE 3871 para la que se ha propuesto una cronología post quem situada entre los años 15 y 10 a.C. y que finaliza en los primeros años del reinado de Tiberio (Guilabert et alii, 2010). En esta misma UE se documenta otro ejemplar de Dressel 3 (TM02-BC-11594), (Fig. 12, no 3), y uno de volutas de tipo indeterminado, los materiales junto a los que aparecen son paredes finas de las formas Mayet XXIV y Mayet XXXIII, TSI de las formas Conspectus $12.1 \mathrm{y}$ 14.1 (Guilabert et alii, 2010).

Sobre otro ejemplar, aunque esta vez procedente del fondo museo, que también presenta decoración en el disco, se aprecia una especie de palmeta (TM195841, sondeo 2, nivel 3), (Fig. 12, n ${ }^{\circ} 5$ ).

Paralelos con estratigrafía se encuentran en Ampurias en el cambio de Era, en un contexto de época augustal del 10 a.C. al 1 d.C. (Aquilué et alii, 2008, 44).

En el pecio de Cala Bona I en un conjunto de materiales del 50-30 a.C. (Martín, 2008, 110). Este mismo yacimiento nos sirve para el ejemplar de Dressel-Ricci 3A (Martín, 2008, 122, n 9) con una datación del 5030 a.C.

En Baetulo se documentan desde la $2^{\mathrm{a}}$ mitad del s. I a.C. hasta inicios del s. VI d.C. (Celis, 2008, 184-185).

En Tarraco se atestigua en un contexto del 100 al 75 a.C. y en otro del 50 al 25 a.C. (Díaz, 2000, 245 y 253).

En Cosa (Italia) siete ejemplares aparecen en un contexto del 175-70 a.C., tres lo hacen en uno del 15070 a.C., dos en el 120-20 a.C., uno en 119/91-70 a.C., tres en 25/20 a.C. a 50 d.C., cuatro desde el 50 hasta el circa 100 y tres del 50 al 225 d.C. (Rickman y Wynick, 1994, 69-73).

Por lo que respecta al tipo Palol 2 B se documenta en Ampurias en el estrato III de la Muralla Robert cuya datación es del tercer $1 / 4$ del siglo I a.C. (Arxé, 1982, 72).

\section{Similar a Dressel-Ricci 3 A}

Es similar a este tipo pero sin las aletas. Procede del fondo de museo (TM66-67, no 1158, 20/D/797), (Fig. $\left.11, n^{\circ} 7\right)$.

\section{DRESSEL 4}

El rasgo distintivo y que la caracteriza son las dos cabezas de ave de largo cuello situadas en el pico cuya forma es de yunque; el depósito es troncocónico. Es una producción hecha a molde. Supone una evolución con respecto a las lucernas de cronología propiamente republicana ya que es más estilizada y sus paredes son delgadas; se enmarca desde época augustea perdurando durante todo el reinado de Tiberio (Morillo, 1999, 311) aunque tradicionalmente suele incluirse en el grupo de las tardorrepublicanas.

En el Tossal de Manises tenemos ocho ejemplares, de los cuales siete proceden de excavaciones con estratigrafía. Las pastas son finas y depuradas y suelen presentar un color beige. Los engobes son de color marrón pudiendo adquirir tonalidades anaranjadas o rojizas, sólo un ejemplar no presenta engobe (Fig. 13, $\mathrm{n}^{\mathrm{o}}$ 7). Uno de los ejemplares (TM92-C/Popilio W/CS. 16727), (Fig. 13, no 5) presenta en el disco decoración vegetal, posiblemente una corona de laurel. En las ocho piezas localizadas observamos multitud de modelos que cambian tanto en su decoración como en sus acabados y tamaños, al igual que ocurre con el resto de lucernas de este tipo procedentes de otros yacimientos. En las colecciones de Herrera de Pisuerga se documentan, al menos, 17 modelos diferentes de matriz quedando demostrado por Morillo (1992, 68-96; 1996, 112) que del análisis de este dato no podían desprenderse observaciones valiosas sobre cronología, taller de origen y área de dispersión para cada variante y que la elección de cada composición decorativa se interpretaba en función de su valor estético (véase también Morillo, 1999, 64).

Los grupos cronológicos por estratigrafía quedan de la siguiente manera:

- Fines s. I a.C. - Tiberio/Claudio: un ejemplar (TM99-SB-2075/CS. 16729, UE 2027), (Fig. 13, $\left.\mathrm{n}^{\mathrm{o}} 7\right)$.

- 30/40 - 50 d.C.: un ejemplar (TM01-BC-4658/CS. 16728, UE 3509), (Fig. 13, no 8).

- Tiberio-Claudio: un ejemplar (TM02-BC-12259, UE 3915), (Fig. 13, no 6).

- 50/65 - 70/100 d.C.: un ejemplar (TM01-BC-4542 y 4784/CS. 13876, UE 3498 y 3523), (Fig. 13, nº 4).

- Siglo II d.C.: un ejemplar (TM01-SB-5815, UE 2195), (Fig. 13, no 12).

- $2^{\mathrm{a}}$ mitad s. II sin llegar a finales del mismo: un ejemplar (TM98/CPO/2088, UE 1069), (Fig. 13, no 9).

- 231-300 d.C.: un ejemplar (TM02-FO-4598, UE 1675), (Fig. 13, no 11).

El ejemplar con la datación más antigua en Lucentum se fecha a partir de finales del siglo I a.C. hasta llegar al reinado de Claudio inclusive.

Por lo que respecta a la cronología de este tipo, Ricci estableció una datación entre el 20 a.C. y el 10 d.C. (Ricci, 1973, 205) pero en Hispania, Galia y Germania se observa una tendencia diferente a la de los ejemplares de procedencia centro-itálica ya que las lucernas 


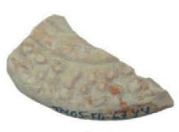

1

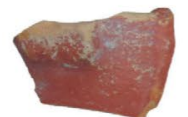

2

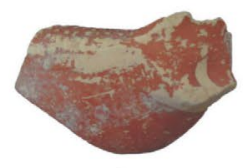

3

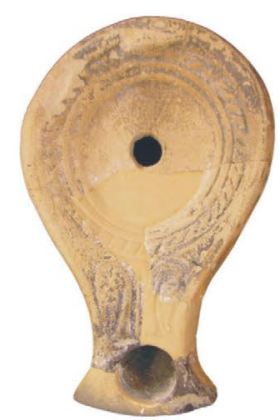

4

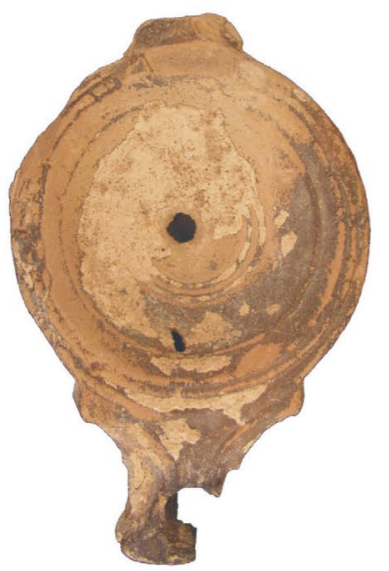

13

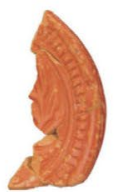

5

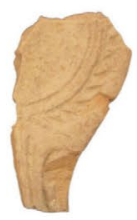

7

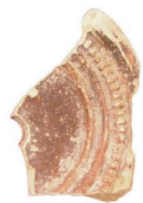

6

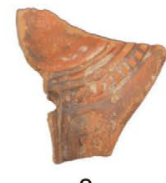

8

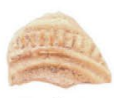

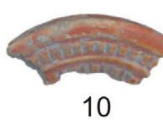

10

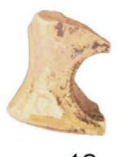

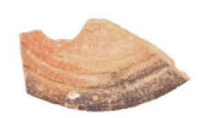

11

Figura 13: Dressel 2/3 ( $n^{\circ} 1,2$ y 3), Dressel 4 ( $n^{\circ} 4$ a 12), Bussière AVI 8e ( $\left.n^{\circ} 13\right)$.

Dressel 4 se siguen produciendo durante el reinado de Tiberio (Morillo, 1992, 56-57; Morillo, 1996, 57-61). Este hecho se aprecia también en Lucentum ya que hay tres ejemplares que alcanzan la época de Claudio y uno más cuya cronología se inicia en el reinado de éste último.

Sin contar los centros originarios en los que se produjo esta forma (Roma, sus alrededores y la Campania), se fabricó también en talleres militares como Haltern, Vetera Castra, Oberaden y Herrera de Pisuerga (Morillo, 1992, 57-69; Morillo, 2015, 348) para abastecer a las guarniciones militares. Aparte del ya mencionado centro de Herrera de Pisuerga, en Hispania se ha localizado en el yacimiento de El Monastil (Elda, Alicante) la pieza inferior de un molde bivalvo que contenía en el fondo interno tres círculos enmarcando la firma L·EROS. Su excavador la ha relacionado con una posible filial de un taller de lucernas de la zona de Ampurias que firmaría bajo dicha leyenda lucernas del tipo Dressel 4 (Poveda, 2012, 366; Poveda, 2013, 459-460). La cronología que se ha establecido para el conjunto es la del último tercio del siglo I a.C. y el primer tercio del siglo I d.C. (Poveda, 2013, 455-467).

Paralelos para este tipo se encuentran en Badalona desde época de Augusto (Celis, 2008, 186-187).

En Herrera de Pisuerga se documentan en la última década del siglo I a.C. hasta Tiberio (Morillo, 1992).

En Astorga en la Casa del pavimento de opus signinum, en la UE 3018, entre el 15/10 a.C. y el 15/20 d.C. (Morillo, 1999, 63).

En Montans (Francia) se le asigna una cronología del s. I a.C. y época augustea para las piezas Dressel 4 allí producidas (Bergès, 1989, 17 y 36). 
En el yacimiento de Saint-Antoine (Fréjus, Francia) se localizan en el Horizonte 3 con una datación del 15-12 a.C. (Rivet, 2008, 782).

En Cosa (Italia) aparece 1 ejemplar en un contexto del 175-70 a.C., 1 del 150-70 a.C., 12 en un contexto del 25/20 a.C.-50 d.C., 5 del 50 a circa 100 d.C. y 2 del 50 al 225 d.C. (Rickman y Wynick, 1994, 79-83).

\section{BusSIÈRE AVI 8E}

Se trata de una lucerna con disco circular y rostrum en forma de yunque aunque ya empieza a esbozarse el arranque de unas volutas.
El caso que nos ocupa procede del fondo museo (CS. 2705/TM-1112 (2), 67-TM-272), (Fig. 13, nº 13) por lo que no aporta datos derivados de su contexto estratigráfico.

\section{MARCAS}

Del total de 1631 lucernas apenas se han conservado 76 marcas, o sea un 4,6\% del total de lucernas la presentan, (75 en la base y una sobre voluta), ya sea completa o incompleta, procedentes tanto de materiales del fondo museo como de las campañas recientes. De esas 76 marcas pertenecientes a lucernas de todo el

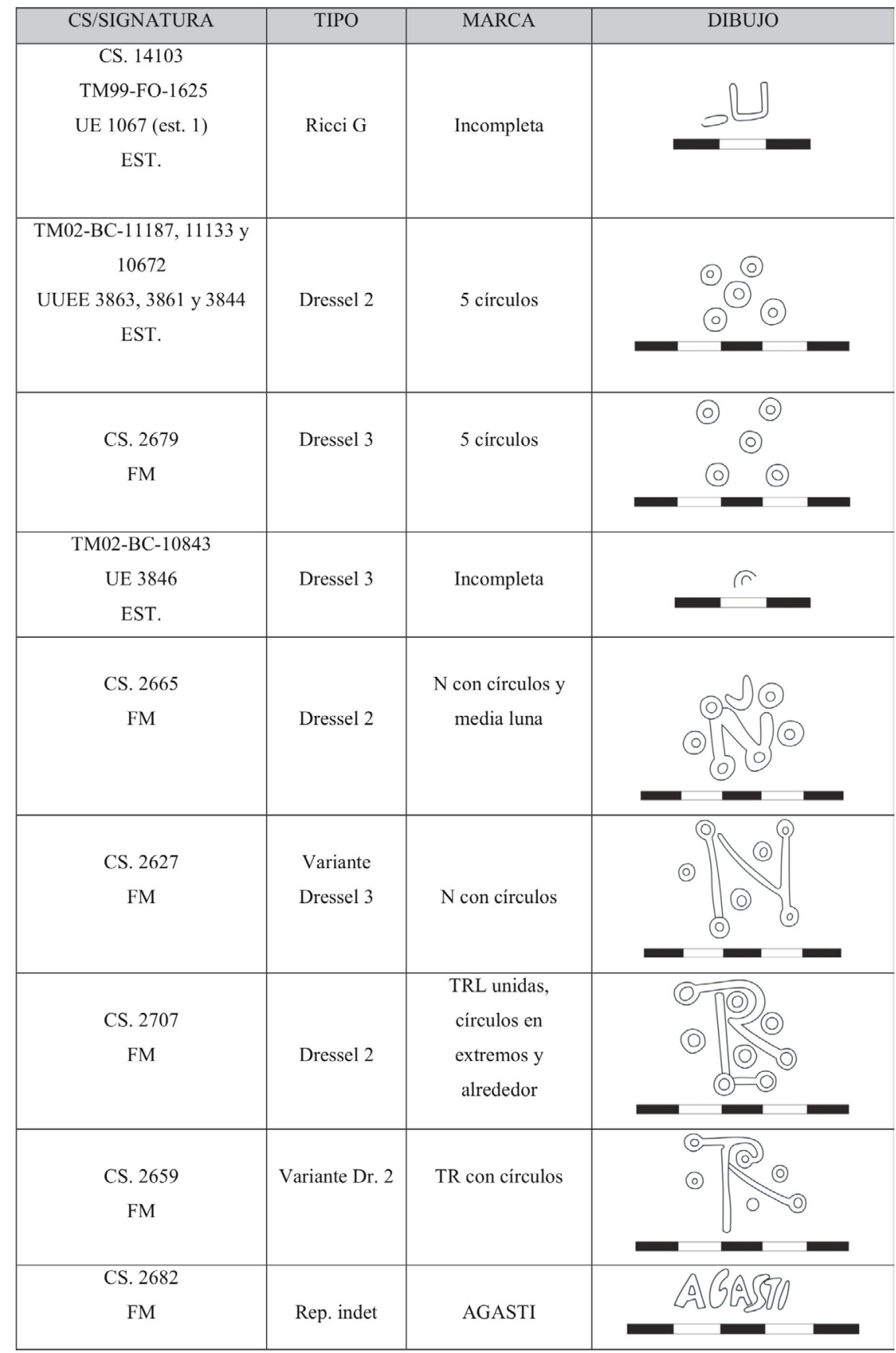

Figura 14: Marcas. 
período romano y de todas las tipologías, el 11,8\% se documentan sobre tipos republicanos.

Las marcas se exponen por orden alfabético, los signos aparecen al final. Los paralelos aportados proceden de contextos con cronología, de esta forma evitamos largos listados con ejemplares del fondo museo que no proporcionan ningún dato de interés. No hemos hecho un estudio exhaustivo de las marcas que recopile toda la información existente sobre ellas sino que presentamos las documentadas en el yacimiento aportando algunos paralelos. A las marcas no se les ha asignado una procedencia exacta ni tampoco aproximada ya que no se han realizado análisis de pastas, en algunas ocasiones se ha sugerido algún posible origen pero sólo siguiendo a los numerosos estudios realizados.

\section{AGASTI}

Aparece únicamente sobre una lucerna tardorrepublicana de tipología indeterminada (CS. 2682) procedente del fondo de museo. Esta marca ya fue publicada por Olcina $(1990,83)$ quien encontró un paralelo incompleto en Cartago (Hayes, 1975, 62, pl. 27 X, 38) de principios del s. I d.C. en el que se leía -ASTI. Olcina se inclina porque nuestro ejemplar pudiera ser una Dressel 3 ya que sobre éste tipo en concreto, aunque también sobre Dressel 4, aparecen firmas.

\section{$\mathrm{N}$}

Está representada en Lucentum por dos ejemplares procedentes del fondo de museo, uno (CS. 2665), (Fig. $8, n^{\circ} 6$ ) es una Dressel 2 y el otro (CS. 2627), (Fig. 11, $n^{\circ} 1$ ) es una variante de la Dressel 3.

Es una marca que aparece en los tipos tardorrepublicanos del siglo I a.C., básicamente Dressel 2 y 3 (Olcina, 1990, 21 y 24).

En Cosa (Rickman y Wynick, 1994, fig. 137) aparece mayoritariamente sobre lucernas del tipo Dressel 2 como vemos en las tres piezas numeradas como 221 , 222 y 225 datadas del 175 al 70 a.C., un ejemplar $\left(n^{\circ}\right.$ 242) fechado entre el $25 / 20$ a.C. y el 50 d.C., cuatro ejemplares (números 259, 263, 264 y 265) enmarcados entre el 50 y c. 100 d.C., otro ejemplar de Dressel 2 ( $\left.n^{\circ} 270\right)$ que se fecha del 100 al 225 d.C. y, por último, un ejemplar de Dressel 3 ( $\left.n^{\circ} 289\right)$ datado entre el 175 y el 70 a.C. En total suman nueve lucernas del tipo Dressel 2 y una del tipo Dressel 3.

\section{TR}

Letras ligadas que aparecen sobre un ejemplar que podría considerarse una variante de la Dressel 2 (CS. 2659), (Fig. 8, no 3 ) procedente del fondo del museo. Olcina $(1990,22)$ la publicó como una única letra, una $\mathrm{R}$, pero cabe la posibilidad de que se trate de dos letras ligadas. La R es bastante frecuente entre los ejemplares tardorrepublicanos. Podría tener relación con la siguiente marca.

\section{TRL}

Marca formada por tres letras ligadas que aparecen sobre una Dressel 2 (CS. 2707), (Fig. 8, n 4) procedente del fondo de museo.

En Cosa (Italia) aparece esta marca, muy similar, sobre los ejemplares 234 y 318, la primera es una Dressel 2 y la segunda una lucerna tardorrepublicana indeterminada, ambas con una cronología del contexto del 150 al 70 a.C. La lectura que proponen los autores para las dos marcas es TRL (Rickman y Wynick, 1994, 59, 77-78, fig. 137). Podría estar relacionada con la anterior TR.

\section{MARCA INCOMPLETA}

Aparece sobre una Ricci G (CS. 14103), (Fig. 7, n 3) fechada a partir de la última década del siglo I a.C. llegando hasta inicios de Tiberio.

\section{Cinco PUntos}

Marca que constatamos en dos ocasiones, en una sobre un ejemplar de Dressel 2 (TM02-BC-11187, 11133 y 10672), (Fig. 8, no 8), procedente de varias UUEE cuya cronología más tardía se ha fijado en la $1^{\mathrm{a}}$ mitad del siglo II d.C., y en otra sobre una Dressel 3 (CS. 2679), (Fig. 11, no 2), procedente del fondo de museo.

La marca sobre Dressel 3 fue publicada por Olcina $(1990,23)$ quien propuso diferentes cronologías para el tipo, siguiendo a Pavolini entre el 90/80 y el 10 a.C., según Ricci en Ventimiglia entre el 70 y el 10 a.C., siguiendo a Arxé en Ampurias entre el 80/70 hasta el 30/25 a.C.

Encontramos tres ejemplares en la obra de Morillo (1999, vol. I, 283-284), los tres sobre lucernas derivadas de la Dressel 3, uno procede de la Casa Pallarés de León y se data entre el 25-50 d.C., otro procede de Astorga con una cronología del 15/10 a.C. al 15/20 d.C., el tercero se fecha desde el cambio de Era hasta el 50 d.C.

En Cosa (Italia) aparece sobre una Dressel 2 con una cronología del contexto del 25/20 a.C. al 50 d.C. (Rickman y Wynick, 1994, fig. 136).

\section{DECORACIONES}

Con respecto a la decoración se han buscado paralelos a los motivos con estratigrafía y procedentes de excavaciones con contexto arqueológico. Se relacionan 

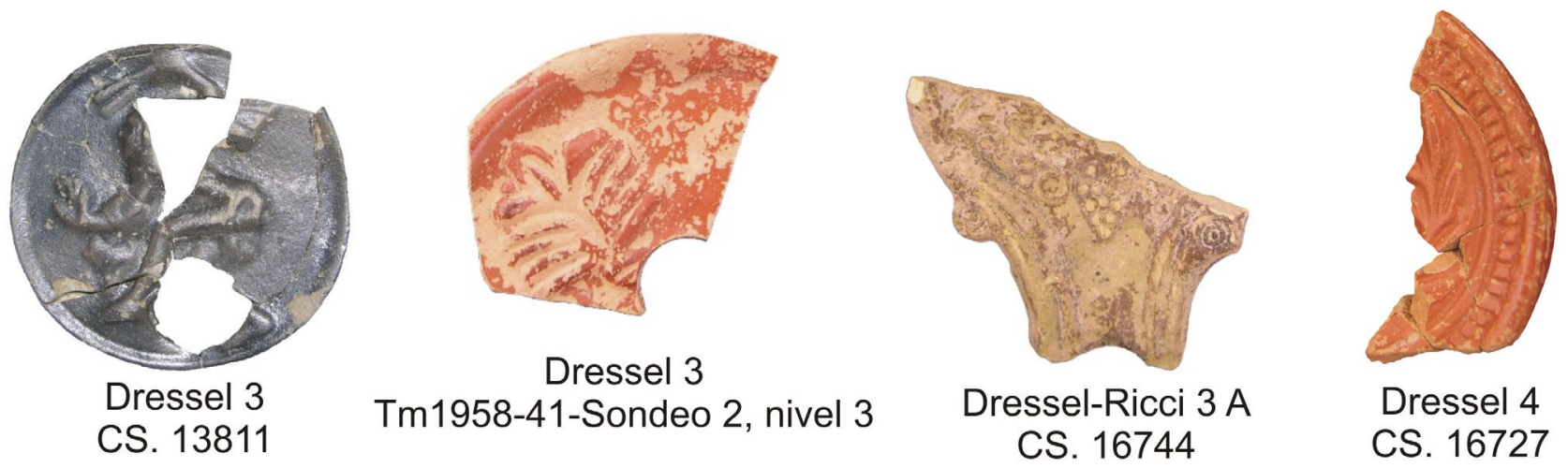

Figura 15: Motivos decorativos representados sobre lucernas republicanas.

también las decoraciones de las piezas procedentes del fondo del museo pero sin asignarles paralelos.

Tras analizar el conjunto en general se aprecia que entre las lucernas republicanas existen pocas piezas decoradas.

A la hora de clasificar los motivos decorativos hemos seguido los grupos que estableció Bailey para las lucernas del Museo Británico, sirviéndonos el grupo III perteneciente a la Vida cotidiana y, dentro de él, el subgrupo «Entretenimientos» y el grupo V que contiene a las Plantas y grupos florales con los subapartados «Racimos» y «Hojas y ramas».

En el subgrupo «Entretenimientos» podemos incluir un motivo formado por un bailarín con bastones documentado sobre una lucerna Dressel 3 (CS. 13811), (Fig. 11, no 3 ; Fig. 15), fechada desde el 15/10 a.C. hasta inicios del reinado de Tiberio. En ella se representa un bailarín de perfil y hacia la izquierda, presenta las piernas flexionadas y el cuerpo inclinado hacia delante con el brazo izquierdo hacia abajo y con dos bastones en la mano derecha, el brazo derecho está levantado por encima de la cabeza.

En el subapartado «Racimos» incluimos un único motivo que se documenta sobre una Dressel-Ricci 3 A (CS. 16744), (Fig. 11, nº 6; Fig. 15), con racimo y sarmientos, fechada estratigráficamente desde el 231 al 300 d.C.

El subgrupo «Hojas y ramas» es bastante abundante ya que aparece representado, en sus distintas manifestaciones, en 12 ocasiones de las que dos son lucernas republicanas, siete de volutas y tres de disco.

Una de estas lucernas republicanas que hemos mencionado es un ejemplar de Dressel 3 (TM195841-Sondeo 2, nivel 3), (Fig. 12, no 5; Fig. 15), sobre la que se representa una especie de palmeta o de hoja de palmera que vemos en la figura 15 . Procede de excavaciones antiguas que no habían adoptado por tanto la metodología arqueológica moderna.

La segunda lucerna republicana es una Dressel 4 (CS. 16727), (Fig. 13, no 5; Fig. 15), con una corona de laurel.

\section{FICHAS DE CATALOGACIÓN}

\section{RICCI B}

Inventario: TM94-20-054, CS. 16769 (Fig.7, $\mathrm{n}^{\circ}$ 1). Procedencia: excavación, UE. 20013.

Cronología del estrato: 130-70 a.C. aprox.

Descripción: fractura escalonada, pasta marrón con inclusiones de fondo transparentes-brillantes, punteadas blancas, pequeñas y grandes grises. Poros, vacuolas y aberturas. Engobe perdido. Falta parte del infundibulum y casi todo el discus.

Material de datación: Campaniense A Lamboglia 36; paredes finas Mayet II; gris ampuritana.

Bibliografía: inédita.

\section{RicCI E}

Inventario: TM-40 (Fig. 7, n ${ }^{\mathrm{o}}$ 2). Procedencia: fondos museo.

Descripción: fractura rugosa, pasta de color marrónanaranjado, inclusiones de fondo transparentes-brillantes. Poros y vacuolas. Engobe de color negro brillante. Se conserva parte del cuerpo, arranque del asa y del disco.

Bibliografía: inédita.

\section{RICCI G}

Inventario: TM99-FO-1625, CS. 14103 (Fig. 7, no 3). Procedencia: excavación, UE. 1067, estancia 1.

Cronología del estrato: a partir última década s. I a.C.inicios Tiberio.

Descripción: fractura lisa-rugosa, pasta gris con inclusiones punteadas y pequeñas gris/negras y transparentes-brillantes. Poros. Engobe negro brillante muy perdido. Falta el asa, parte de la base y del infundibulum. En la base una marca incompleta. Decoración radial en la margo.

Material de datación: en esta UE destaca la ausencia de sigillatas, los materiales más modernos son ánforas 
Dressel 7/11 y Dressel 2-4 y paredes finas Mayet XII o XIV.

Bibliografía: Guilabert et alii, 2010.

Inventario: TM02-BC-10340 (Fig. 7, no 4). Procedencia: limpieza perfil excavación, UE. 0000.

Descripción: fractura lisa-rugosa, pasta gris con inclusiones de fondo brillantes y blancas. Poros y vacuolas. Engobe de color gris bastante erosionado. Se conserva parte de la margo, del disco y del orificio de alimentación centrado y del infundibulum.

Bibliografía: inédita.

\section{RICCI H}

Inventario: TM-6571, CS. 3106 (Fig. 7, n ${ }^{\text {5). Proce- }}$ dencia: fondos museo.

Descripción: fractura rugosa, pasta anaranjada con inclusiones punteadas y pequeñas gris/negras y transparentes-brillantes. Vacuolas.

Bibliografía: Olcina, 1990, 19 nº 3.

Inventario: TM-6522, CS. 2648 (Fig. 7, no 6). Procedencia: fondos museo.

Descripción: fractura lisa, pasta tipo sándwich roja al exterior e interior y marrón oscura en el centro, inclusiones de fondo blancas. Poros. Sin engobe. Falta el disco y buena parte del depósito.

Bibliografía: Lafuente Vidal, 1957, 41-42, fig. 10.f; Lafuente Vidal, 1959, lámina VII; Olcina et alii, 1990, $19 \mathrm{n}^{\circ} 4$.

Inventario: TM01-BC-2327 (Fig. 7, $\mathrm{n}^{\mathrm{o}}$ 7). Procedencia: excavación, UE. 3056.

Cronología del estrato: 40/30 a.C.- cambio de era.

Descripción: fractura lisa-rugosa, pasta anaranjada con inclusiones punteadas blancas. Poros. Sin engobe. Se conserva parte del disco y margo.

Material de datación: cerámica ibérica pintada, ánfora, ánfora púnica, cocina.

Bibliografía: inédita.

\section{DRESSEL 1}

Inventario: TM00-SB-5549 y TM00-SB-5369 (Fig. 7, $\mathrm{n}^{\circ}$ 8). Procedencia: excavación, UE. 2389 (estancia III, hab. A9) y 2392 (estancia III, hab. A-b).

Cronología del estrato: tardorrepublicana o inicios del mandato de Augusto.

Descripción: fractura lisa-rugosa, pasta gris con inclusiones de fondo y pequeñas transparentes-brillantes y pequeñas blancas. Poros y vacuolas. Engobe erosionado de color gris oscuro. Se conservan dos fragmentos de margo. Decoración radial en la parte superior del cuerpo. Material de datación: ánfora grecoitálica, campaniense A plato Lamboglia 36.

Bibliografía: inédita.

\section{DRESSEL 2}

Inventario: TM/C-6543, 6575, CS. 2675 (Fig. 8, $\mathrm{n}^{\circ}$ 1). Procedencia: fondos museo.

Descripción: fractura lisa-rugosa, pasta de color beige-rosado, inclusiones de fondo transparentes-brillantes y punteadas blancas. Falta de macroporosidad. Engobe rojizo. Decoración de perlas en relieve. En la zona de arranque del rostrum tres protuberancias borrosas de las que la central podría ser una cabeza. Bibliografía: Olcina et alii, 1990, $20 \mathrm{n}^{\circ} 6$.

Inventario: TM01-BC-16172 y 16173 (Fig. 8, no 2). Procedencia: excav., UUEE. 3441 y 3433 (hab. 5).

Cronología del estrato: 40/30 a.C. hasta el cambio de era.

Descripción: fractura lisa-rugosa. Pasta de color beige con inclusiones de fondo y punteadas transparentesbrillantes. Vacuolas y aberturas. Engobe rojo-anaranjado. Decoración de perlas en relieve. Impresión de dos círculos en el arranque del rostrum.

Material de datación: 3441 (ánfora grecoitálica, barniz negro ibicenco de pasta gris, cerámica ibérica pintada), 3433 (Campaniense A Lamboglia 36, 33 a, 68bc, Campaniense A tardía Lamboglia 31b, Campaniense B-oide Lamboglia 2 y 5, gris ampuritana, paredes finas Mayet III, ánforas púnico-ebusitanas, Dressel 1 y grecoitálicas).

Bibliografía: inédita.

Inventario: TM-6524, F-508, CS. 2659 (Fig.8, no 3). Procedencia: fondos museo.

Tipología: variante de la Dressel 2.

Descripción: fractura lisa-escalonada. Pasta de color beige. Inclusiones punteadas transparentes-brillantes. Falta de macroporosidad. Engobe rojo-anaranjado. Marca en la base formada por la ligadura de las letras TR con círculos alrededor.

Bibliografía: Figueras, 1971, $138 \mathrm{n}^{0}$ 508; Olcina et alii, $1990,22 \mathrm{n}^{\circ} 8$.

Inventario: TM-1139(2), CS. 2707 (Fig. 8, no 4). Procedencia: fondos museo.

Descripción: fractura rugosa, pasta de color beige, inclusiones pequeñas gris-negras. Vacuolas. Engobe rojoanaranjado y marrón. Faltan el asa y el rostrum. Marca en la base formada por la ligadura de las letras TRL con puntos alrededor. Decoración de perlas en relieve. Bibliografía: inédita.

Inventario: TM-6568, CS. 2642 (Fig. 8, $n^{\circ}$ 5). Procedencia: fondos museo.

Descripción: fractura rugosa, pasta de color beige, se aprecia una inclusión grande de color blanco. Falta de macroporosidad. Engobe de color marrón semibrillante. Le faltan el asa y parte del rostrum que han sido reconstruidos. Decoración de perlas en relieve. Tres puntos impresos en el arranque del rostrum. Bibliografía: Olcina et alii, 1990, $20 \mathrm{n}^{\circ} 5$. 
Inventario: TM-6526, CS. 2665 (Fig. 8, nº 6). Procedencia: fondos museo.

Descripción: fractura rugosa, pasta de color beige, inclusiones de fondo transparentes-brillantes y punteadas blancas. Falta de macroporosidad. Engobe marrón-anaranjado. Faltan el asa y el rostrum que han sido reconstruidos. Marca en la base formada por la letra $\mathrm{N}$ con puntos alrededor y media luna sobre ella. En la margo decoración vegetal a base de pámpanos, sarmientos y racimos de uva. Dos círculos impresos en el arranque del rostrum.

Bibliografía: Olcina et alii, 1990, $21 \mathrm{n}^{0} 7$.

Inventario: TM-40 (Fig. 8, $\mathrm{n}^{\mathrm{o}}$ 7). Procedencia: fondos museo.

Descripción: fractura lisa-rugosa. Pasta de color beigeanaranjado. Inclusiones de pequeño tamaño de color blanco y brillantes de fondo. Poros y vacuolas. Engobe rojizo-anaranjado. Decoración de perlas en relieve. Un círculo en el rostrum.

Bibliografía: inédita.

Inventario: TM02-BC-11187, 11133 y 10672 (Fig. 8, $\mathrm{n}^{\circ}$ 8). Procedencia: excavación, UUEE. 3863 y 3844. Cronología del estrato: 3844 es de la $1^{\text {a }}$ mitad s. II d.C. y 3863 del 30 al 50 d.C.

Descripción: fractura lisa-escalonada, pasta de color beige con inclusiones de fondo transparentes-brillantes. Poros. Engobe rojo-anaranjado. Marca impresa en la base formada por cinco círculos. Decoración de perlas en relieve.

Material de datación: TSI y TSAA.

Bibliografía: inédita.

Inventario: TM98/T-VI/216 (Fig. 9, $\mathrm{n}^{\mathrm{o}}$ 1). Procedencia: excavación, UE. 1040.

Cronología del estrato: época Flavia.

Descripción: fractura lisa, pasta de color beige con inclusiones de fondo transparentes-brillantes. Poros y vacuolas. Engobe rojo-anaranjado. Se conserva parte de la margo, del disco y arranque del rostrum. Decoración de perlas en relieve.

Material de datación: cerámica ibérica pintada, paredes finas, campaniense A.

Bibliografía: inédita.

Inventario: TM02-BC-12513 (Fig. 9, nº 2). Procedencia: excavación, UE. 3921.

Cronología del estrato: 40/30 a.C. hasta 40 d.C.

Descripción: fractura rugosa, pasta de color beige-rosado con inclusiones pequeñas transparentes-brillantes. Vacuolas y aberturas. Engobe rojo-anaranjado. Se conserva parte de la margo, disco y aleta lateral. Decoración de perlas en relieve.

Material de datación: ánfora romana Dressel 1 B, paredes finas Mayet III, terra sigillata itálica.

Bibliografía: inédita.
Inventario: TM05-FO-12620 (Fig. 9, nº 3). Procedencia: excavación, UE. 5397.

Cronología del estrato: 100-150 d.C.

Descripción: fractura lisa-rugosa. Pasta de color marrón con el centro grisáceo. Inclusiones de fondo transparentes-brillantes y punteadas blancas. Poros y vacuolas. Engobe rojo-anaranjado. Se conserva parte de la margo y discus. Decoración de pámpanos y racimos en relieve.

Material de datación: TSG forma Dragendorff 37; TSAA.

Bibliografía: inédita.

Inventario: TM01-BC-3370 (Fig. 9, no 4). Procedencia: excavación, UE. 3414.

Cronología del estrato: 50-65 d.C.

Descripción: fractura lisa, pasta de color marrón-anaranjado. Inclusiones pequeñas y punteadas blancas. Poros. Engobe rojo-anaranjado. Decoración de perlas en relieve.

Material de datación: campaniense A Lamboglia 36; paredes finas Mayet III y Mayet IV.

Bibliografía: inédita.

Inventario: TM05-FO-10688 (Fig. 9, $\mathrm{n}^{\circ}$ 5). Procedencia: excavación, UE. 5133.

Cronología del estrato: 100-230 d.C.

Descripción: fractura lisa. Pasta de color marrón con inclusiones de fondo transparentes-brillantes. Falta de macroporosidad. Engobe de color negro con irisaciones metálicas. Decoración de perlas en relieve.

Material de datación: paredes finas Mayet XXXIII y TSI.

Bibliografía: inédita.

Inventario: TM01-BC-8639 (Fig. 9, $\mathrm{n}^{\circ}$ 6). Procedencia: excavación, UE. 3696.

Cronología del estrato: desde 40/30 a.C. hasta 50 d.C. Descripción: fractura rugosa. Pasta de color rojo. Inclusiones de fondo transparentes-brillantes. Poros. Engobe de color rojo-anaranjado. Decoración de perlitas en relieve.

Material de datación: barniz negro ibicenco de pasta gris y TSI.

Bibliografía: inédita.

Inventario: TM94-28-20 (Fig. 9, $\mathrm{n}^{\circ}$ 7). Procedencia: excavación, UE. 28002.

Cronología del estrato: época augustea.

Descripción: fractura lisa. Pasta de color anaranjado. Inclusiones de fondo transparentes-brillantes. Poros y vacuolas. Engobe de color rojizo. Decoración de perlas en relieve.

Material de datación: itálica de cocina Vegas 14.

Bibliografía: inédita.

Inventario: TM02-BC-11958 (Fig. 9, no 8). Procedencia: excavación, UE. 3846.

Cronología del estrato: 50-65 d.C. 
Descripción: fractura escalonada. Pasta de color beige. Inclusiones de fondo y punteadas transparentesbrillantes. Poros. Engobe de color rojo-anaranjado. Decoración de perlitas en relieve.

Material de datación: paredes finas Mayet X-XI, Mayet XII ó XIV, Mayet XXVIII/XXIX; TSI Conspectus Formarum 22.5.

Bibliografía: inédita.

Inventario: TM02-BC-14134 (Fig. 10, $\mathrm{n}^{0}$ 1). Procedencia: excavación, UE. 3977.

Cronología del estrato: 50-65 d.C.

Descripción: fractura lisa. Pasta de color marrón. Inclusiones de fondo blancas. Poros. Engobe marrón oscuro. Decoración de perlitas en relieve.

Material de datación: paredes finas Mayet XXXVII.1. Bibliografía: inédita.

Inventario: TM02-BC-10884 (Fig. 10, $\mathrm{n}^{0}$ 2). Procedencia: excavación, UE. 3846.

Cronología del estrato: 50-65 d.C.

Descripción: fractura lisa-escalonada. Pasta de color marrón-anaranjado. Inclusiones de fondo transparentes-brillantes y punteadas blancas y gris/negras. Poros y vacuolas. Engobe rojo amarronado. Decoración de perlitas en relieve.

Material de datación: paredes finas Mayet X-XI, Mayet XXVIII; TSI Conspectus Formarum 22.5.

Bibliografía: inédita.

Inventario: TM02-BC-14642 (Fig. 10, $\mathrm{n}^{\mathrm{o}}$ 3). Procedencia: excavación, UE. 3771.

Cronología del estrato: $2^{\mathrm{a}}$ mitad s. II-primer $1 / 3 \mathrm{~s}$. III d.C.

Descripción: fractura lisa. Pasta de color marrón. Falta de inclusiones y de macroporosidad. Engobe marrón oscuro. Decoración de perlas en relieve.

Material de datación: paredes finas Mayet XXXIV, Mayet XXXVII y Mayet XLII; TSG formas Dragendorff 29 b y Dragendorff 24/25.

Bibliografía: inédita.

Inventario: TM01-BC-4405 (Fig. 10, nº 4). Procedencia: excavación, UE. 3512.

Cronología del estrato: 40/30 a.C.-cambio de era.

Descripción: fractura lisa. Pasta de color beige. Inclusiones de fondo transparentes-brillantes. Falta de macroporosidad. Engobe rojizo. Decoración de perlas en relieve.

Material de datación: campaniense B-oide Lamboglia 5 , cerámica itálica de cocina.

Bibliografía: inédita.

Inventario: TM02-BC-14172 (Fig. 10, $\mathrm{n}^{\mathrm{0}}$ 5). Procedencia: excavación, UE. 3982.

Cronología del estrato: 50-65 d.C.

Descripción: fractura lisa. Pasta de color amarillento. Falta de inclusiones y de macroporosidad. Engobe negro. Decoración de perlas en relieve.
Material de datación: TSI Conspectus Formarum 12.3-4; paredes finas Mayet III y Mayet XXIV.

Bibliografía: inédita.

Inventario: TM02-BC-14171 (Fig. 10, $\mathrm{n}^{\mathrm{o}}$ 6). Procedencia: excavación, UE. 3982.

Cronología del estrato: 50-65 d.C.

Descripción: fractura lisa. Pasta de color beige. Inclusiones de fondo transparentes-brillantes. Falta de macroporosidad. Engobe rojo-anaranjado. Decoración de perlas en relieve.

Material de datación: TSI Conspectus Formarum 12.3-4; paredes finas Mayet III y Mayet XXIV.

Bibliografía: inédita.

Inventario: TM01-FO-2480 (Fig. 10, ${ }^{\circ}$ 7). Procedencia: excavación, UE. 1508.

Cronología del estrato: época moderna.

Descripción: fractura lisa-rugosa. Pasta de color beige claro. Inclusiones de fondo brillantes y punteadas blancas. Poros. Engobe amarronado. Decoración de perlas en relieve.

Bibliografía: inédita.

Inventario: TM98/T-VI/349 (Fig. 10, no 8). Procedencia: excavación, UE. 1036.

Cronología del estrato: inicios época flavia.

Descripción: fractura lisa. Pasta de color beige. Inclusiones de fondo transparentes-brillantes. Poros y vacuolas. Engobe rojizo. Decoración de perlas en relieve.

Material de datación: TSG; africana de cocina Ostia III, 332; ánfora púnico-ebusitana 25.

Bibliografía: inédita.

Inventario: TM09-FO-14762 (Fig. 10, n ${ }^{\circ}$ 9). Procedencia: excavación, UE. 5854.

Cronología del estrato: 30-15 a.C.

Descripción: fractura lisa-rugosa. Pasta de color gris claro. Inclusiones de fondo brillantes y punteadas de color gris. Poros. Engobe gris. Decoración de perlas en relieve.

Material de datación: cerámica de cocina púnicoebusitana, sartén forma Celsa 84.13596, cubilete de paredes finas forma Mayet II.

Bibliografía: inédita.

Inventario: TM-40 (Fig. 10, $\mathrm{n}^{\circ}$ 10). Procedencia: fondos museo.

Descripción: fractura lisa-rugosa. Pasta de color beige claro. Inclusiones de fondo de color blanco y brillantes. Poros. Engobe rojizo-anaranjado, más oscuro en la zona del rostrum. Decoración de líneas paralelas $\mathrm{y}$, entre ellas, perlas en relieve. Dos círculos en el rostrum.

Bibliografía: inédita.

Inventario: TM01-BC-195 (Fig. 10, nº 11). Procedencia: excavación, UE. 3000. 
Cronología del estrato: época moderna.

Descripción: fractura lisa-rugosa. Pasta de color beige-rosado. Inclusiones punteadas de color blanco y de fondo brillantes. Poros. Engobe rojizo-anaranjado. Decoración de perlas en relieve y tres trazos en paralelo. Material de datación: es una UE superficial.

Bibliografía: inédita.

Inventario: TM09-FO-14100 (Fig. 10, no 12). Procedencia: excavación, UE. 5861.

Cronología del estrato: 30-15 a.C.

Descripción: fractura lisa. Pasta de color beige claro. Inclusiones de fondo brillantes. Poros. Engobe rojizoanaranjado. Decoración de perlas en relieve.

Material de datación: UE previa a la llegada de TSI y de las ánforas altoimperiales, aparecen ánforas Dr. 1 $\mathrm{A}$ y Mañà C2b, Campanienses A, B y barnices negros de pasta gris.

Bibliografía: inédita.

Inventario: TM66/67-1154 (Fig. 10, nº 13). Procedencia: fondos museo.

Descripción: fractura lisa-rugosa. Pasta de color beige. Inclusiones de pequeño tamaño de color blanco y medio de color rojizo. Poros y vacuolas. Engobe rojizoanaranjado-marrón. Decoración de perlas en relieve. Bibliografía: inédita.

\section{DRESSEL $2 / 3$}

Inventario: TM05-FO-6744 (Fig. 13, n 1). Procedencia: excavación, UE. 4506.

Cronología del estrato: post necrópolis islámica.

Descripción: fractura rugosa. Pasta de color beige claro. Inclusiones de fondo brillantes. Poros. Engobe rojizo-anaranjado. Se conserva una pequeña parte del disco y parte de la margo con perlas en relieve.

Bibliografía: inédita.

Inventario: TM01-BC-5542 (Fig. 13, no 2). Procedencia: excavación, UE. 3061.

Cronología del estrato: 50-65 d.C.

Descripción: fractura rugosa. Pasta de color anaranjado. Inclusiones de fondo transparentes-brillantes y punteadas blancas. Poros y vacuolas. Engobe rojizo. Se conserva una perla en relieve.

Material de datación: TSI Conspectus Formarum 33.1. Bibliografía: inédita.

Inventario: TM99-SB-2416 (Fig. 13, no 3). Procedencia: excavación, UE. 2046.

Tipología: Dressel 2/3. Cronología del estrato: 220-50 a.C.

Descripción: fractura lisa. Pasta de color beige. Inclusiones de fondo transparentes-brillantes y punteadas blancas y gris/negras. Poros y vacuolas. Engobe rojoanaranjado. Decoración de perlitas en relieve.
Material de datación: ánfora púnica Ribera G, campaniense A forma Lamboglia 27 a-b.

Bibliografía: inédita.

\section{DRESSEL 3}

Inventario: TM-6523, CS. 2627 (Fig. 11, nº 1). Procedencia: fondos museo.

Tipología: variante de la Dressel 3, Palol 2B, similar a Leibundgut II.

Descripción: fractura lisa. Pasta de color beige, inclusiones de fondo transparentes-brillantes. Falta de macroporosidad. Engobe rojo-anaranjado brillante. Marca en la base formada por una $\mathrm{N}$ con círculos.

En la zona de arranque del rostrum tres círculos impresos.

El tipo Palol 2B se documenta en Ampurias en el estrato III de la Muralla Robert en el tercer $1 / 4$ del siglo I a.C.

Bibliografía: Olcina et alii, 1990, 24 nº 10.

Inventario: TM-6515, CS. 2679 (Fig. 11, no 2). Procedencia: fondos museo.

Descripción: fractura lisa-escalonada, pasta de color beige, inclusiones punteadas blancas y transparentesbrillantes. Vacuolas. Engobe rojo-anaranjado. Marca en la base formada por cinco círculos.

Bibliografía: Olcina et alii, 1990, 23 n 9.

Inventario: TM02-BC-11593, CS. 13811 (Fig. 11, n 3). Procedencia: excavación, UE. 3871.

Cronología del estrato: 15/10 a.C.- inicios reinado de Tiberio.

Descripción: fractura lisa-escalonada. Pasta de color gris. Inclusiones punteadas transparentes-brillantes. Vacuolas. Engobe gris oscuro semibrillante. Decoración en el disco formada por un bailarín con dos bastones.

Material de datación: un ejemplar de volutas de tipo indeterminado, paredes finas de las formas Mayet XXIV y Mayet XXXIII, TSI de las formas Conspectus 12.1 y 14.1 .

Bibliografía: Guilabert et alii, 2010.

Inventario: TM01-BC-1576 (Fig. 11, n 4). Procedencia: excavación, UE. 3157 (hab. 3).

Cronología del estrato: $2^{\mathrm{a}}$ mitad s. II-primer $1 / 3 \mathrm{~s}$. III d.C.

Descripción: fractura lisa. Pasta de color beige. Inclusiones de fondo blancas. Poros. Engobe marrón-rojizo. Material de datación: TSAA Lamboglia 2 b, Lamboglia 4/36 B, Lamboglia 23; africana de cocina Lamboglia 10 A y Ostia III, 267.

Bibliografía: inédita

Inventario: TM02-BC-13535 (Fig. 11, no 5). Procedencia: excavación, UE. 3766. 
Cronología del estrato: $2^{\mathrm{a}}$ mitad s. II-primer $1 / 3 \mathrm{~s}$. III d.C.

Descripción: fractura lisa. Pasta de color gris. Inclusiones de fondo transparentes-brillantes. Poros y vacuolas. Engobe gris oscuro. En el disco se conserva parte de un círculo sogueado.

Material de datación: paredes finas Mayet XXXVIIB, Mayet XXXVII.1, Mayet XLII; TSG copa Dragendorff 27; TSAA.

Bibliografía: inédita

Inventario: TM02-FO-4550, CS. 16744 (Fig. 11, nº 6). Procedencia: excavación, UE. 1675.

Tipología: similar a Dressel-Ricci 3 A. Cronología del estrato: 231-300.

Descripción: fractura lisa-rugosa. Pasta de color amarillo-verdoso. Inclusiones pequeñas y grandes negras. Poros. Engobe marrón. Decoración: en el disco motivos vegetales a base de sarmientos y un racimo de uvas, éste en el inicio del canal.

Material de datación: TSAA Lamboglia 23.

Paralelos: Martín, 2008, 122 n 9, datación del 50-30 a.C.

Bibliografía: inédita

Inventario: TM66-67, $\mathrm{n}^{\mathrm{o}}$ 1158, 20/D/797 (Fig. 11, $\mathrm{n}^{\mathrm{o}}$ 7). Procedencia: fondos museo.

Tipología: similar a Dressel-Ricci 3 A pero sin aletas. Descripción: fractura rugosa. Pasta de color marrón, inclusiones de fondo transparentes-brillantes, punteadas y pequeñas blancas. Poros. Engobe marrón-anaranjado.

Bibliografía: inédita.

Inventario: TM67-1139 (Fig. 11, no 8). Procedencia: fondos museo.

Tipología: variante de la Dressel 3, Palol 2B, similar a Leibundgut II.

Descripción: fractura lisa. Pasta de color beige, inclusiones de fondo blancas. Poros. Engobe marrón-anaranjado.

El tipo Palol 2B se documenta en Ampurias en estrato III de la Muralla Robert en el tercer $1 / 4$ del s. I a.C.

Bibliografía: inédita.

Inventario: TM02-BC-11997 (Fig. 11, no 9). Procedencia: excavación, UE. 3846.

Tipología: variante de Dressel 3, similar a Leibundgut II. Cronología del estrato: 50-65 d.C.

Descripción: fractura lisa-rugosa. Pasta beige. Inclusiones de fondo transparentes-brillantes y punteadas blancas. Poros y vacuolas. Engobe anaranjado.

Material de datación: paredes finas Mayet X-XI, Mayet XXVIII; TSI Conspectus Formarum 22.5.

Bibliografía: inédita

Inventario: TM02-BC-10843 (Fig. 11, n ${ }^{\circ}$ 10). Procedencia: excavación, UE. 3846.

Cronología del estrato: 50-65 d.C.
Descripción: fractura lisa-escalonada. Pasta de color marrón. Inclusiones de fondo y punteadas blancas y transparentes-brillantes. Poros. Engobe marrón. En la base parte de una marca de la que se ha conservado un círculo. En el arranque del rostrum impresión de dos círculos.

Material de datación: paredes finas Mayet X-XI, Mayet XXVIII; TSI Conspectus Formarum 22.5.

Bibliografía: inédita

Inventario: TM02-BC-11188a (Fig. 12, $\mathrm{n}^{\mathrm{o}}$ 1). Procedencia: excavación, UE. 3863.

Cronología del estrato: 30-50 d.C.

Descripción: fractura lisa. Pasta de color beige. Inclusiones de fondo transparentes-brillantes. Falta de macroporosidad. Engobe rojo-anaranjado.

Material de datación: TSI.

Bibliografía: inédita

Inventario: TM01-BC-4427 (Fig. 12, $\mathrm{n}^{\circ}$ 2). Procedencia: excavación, UE. 3512.

Cronología del estrato: 40/30 a.C.-cambio de era.

Descripción: fractura escalonada. Pasta de color beige. Inclusiones de fondo transparentes-brillantes y blancas. Falta de macroporosidad. Engobe rojizo.

Material de datación: campaniense B-oide Lamboglia 5 , cerámica itálica de cocina.

Bibliografía: inédita

Inventario: TM02-BC-11594 (Fig. 12, $\mathrm{n}^{\mathrm{o}}$ 3). Procedencia: excavación, UE. 3871.

Cronología del estrato: 15/10 a.C.- inicios reinado de Tiberio.

Descripción: fractura lisa. Pasta de color beige. Inclusiones de fondo transparentes-brillantes. Poros. Engobe rojo-anaranjado.

Material de datación: un ejemplar de volutas de tipo indeterminado, paredes finas de las formas Mayet XXIV y Mayet XXXIII, TSI de las formas Conspectus 12.1 y 14.1 .

Bibliografía: Guilabert et alii, 2010.

Inventario: 67TM 444 (Fig. 12, $\mathrm{n}^{\circ}$ 4). Procedencia: fondos museo.

Descripción: fractura lisa, pasta de color beige claro, inclusiones de fondo brillantes y una de mediano tamaño de color blanco. Poros. Engobe anaranjado-marrón. Bibliografía: inédita.

Inventario: TM-41, sondeo 2, nivel 3, 1958 (Fig. 12, $\mathrm{n}^{\mathrm{o}}$ 5). Procedencia: fondos museo.

Descripción: fractura lisa, pasta de color beige-rosado, inclusiones de fondo brillantes y punteadas blancas. Poros y vacuolas. Engobe rojo-anaranjado. Como decoración presenta una palmeta en el disco.

Bibliografía: inédita.

Inventario: TM75, 21/B/823, TM7233 (Fig. 12, n 6 ). Procedencia: fondos museo. 
Descripción: fractura lisa, pasta de color beige clarogrisáceo, escasas inclusiones de fondo brillantes y blancas. Poros. Engobe marrón.

Bibliografía: inédita.

Inventario: TM09-FO-13459 (Fig. 12, nº 7). Procedencia: excavación, UE. 5738.

Cronología del estrato: 230-280 d.C.

Descripción: fractura lisa-rugosa. Pasta de color beige-rosado. Inclusiones de fondo brillantes, rojizas y blancas. Poros. Engobe rojo-anaranjado. Presenta perlas en relieve.

Material de datación: TSA A.

Bibliografía: inédita.

Inventario: TM02-BC-11188b (Fig. 12, nº 8). Procedencia: excavación, UE. 3863.

Cronología del estrato: 30-50 d.C.

Descripción: fractura lisa. Pasta de color beige-rosado. Inclusiones de fondo brillantes y rojizas. Poros. Engobe rojo-anaranjado. Se trata de un asa.

Material de datación: TSI.

Bibliografía: inédita.

Inventario: TM10-CTP-1164 (UE 7081) y TM10CTP-2281 (UE 7106) (Fig. 12, nº 9). Procedencia: excavación, UUEE. 7081 y 7106.

Cronología del estrato: UE 7081 (s. II-inicios s. V d.C.), UE 7106 (siglos IV-VII d.C.).

Descripción: fractura lisa-rugosa. Pasta de color beige claro. Inclusiones de fondo brillantes y blancas. Falta de macroporosidad. Engobe naranja-marrón.

Material de datación: UE 7106: terra sigillata africana D; UE 7081: cerámica africana de cocina formas Lamboglia 9 A, Lamboglia 10 A y Ostia III, 267.

Bibliografía: inédita.

Inventario: TM02-BC-11117 (Fig. 12, no 10). Procedencia: excavación, UE. 3859.

Tipología: posible Dressel 3. Cronología del estrato: $1^{\mathrm{a}}$ mitad s. II d.C.

Descripción: fractura lisa-rugosa. Pasta amarillenta. Inclusiones punteadas negras. Poros. Engobe marrón.

Decoración: en el canal creado entre las volutas aparece el extremo de una hoja.

Material de datación: ánfora Haltern 70; paredes finas Mayet XVI; plato rojo pompeyano Luni 2/4; TSI Conspectus Formarum 1.1.

Bibliografía: inédita

\section{DRESSEL 4}

Inventario: TM01-BC-4542 y 4784, CS. 13876 (Fig. 13, $\mathrm{n}^{\circ} 4$ ). Procedencia: excavación, UUEE. 3498 y 3523 .

Cronología del estrato: la UE 3498 comprende del 50 al 65 d.C. y la UE 3523 del 70 al 100 d.C.
Descripción: fractura lisa-escalonada. Pasta fina beige. Inclusiones de fondo y punteadas de color rojo y grisnegras. Vacuolas. Engobe marrón. Ejemplar sin asa. Material de datación: UE. 3523: TSI Conspectus Formarum 22; paredes finas Mayet XXXIII y Mayet XXIV; UE. 3498: paredes finas Mayet XXXVII. 1, TSG.

Bibliografía: inédita.

Inventario: TM92-C/Popilio W, CS. 16727 (Fig. 13, nº 5). Procedencia: excavación, UE. 1014.

Cronología del estrato: tercer o último $1 / 4 \mathrm{~S}$. II - fines tercer $1 / 4 \mathrm{~S}$. I a.C.

Descripción: fractura lisa-rugosa. Pasta marrón. Inclusiones de fondo transparentes-brillantes y pequeñas de color gris-negro. Poros y vacuolas. Engobe marrónanaranjado. En el disco decoración vegetal de la que se conserva una parte de una corona de laurel.

Material de datación: campaniense B píxide Lamboglia 3, olla de cocina púnico-ebusitana.

Bibliografía: inédita.

Inventario: TM02-BC-12259 (Fig. 13, nº 6). Procedencia: excavación, UE. 3915.

Cronología del estrato: del 30 al 40 d.C.

Descripción: fractura lisa. Pasta beige. Falta de inclusiones. Engobe marrón oscuro.

Material de datación: paredes finas Mayet XXXIII; TSI plato Conspectus Formarum 18.2; TSG.

Bibliografía: inédita.

Inventario: TM99-SB-2075, CS. 16729 (Fig. 13, nº 7). Procedencia: excavación, UE. 2027.

Cronología del estrato: fines s. I a.C.-Tiberio/Claudio. Descripción: fractura lisa. Pasta beige. Inclusiones pequeñas y punteadas blancas y transparentes-brillantes. Poros. No presenta engobe.

Material de datación: paredes finas Mayet X-XI; TSI; campaniense B-oide plato Lamboglia 7/Morel 2280. Bibliografía: inédita.

Inventario: TM01-BC-4658, CS. 16728 (Fig. 13, nº 8). Procedencia: excavación, UE. 3509.

Cronología del estrato: 30/40-50 d.C.

Descripción: fractura rugosa. Pasta marrón. Inclusiones de fondo gris-negras. Poros y vacuolas. Engobe marrón-anaranjado.

Material de datación: paredes finas Mayet XXIV, Mayet XXXIII; TSI Conspectus Formarum 18.2, 19.2, $22.1,28$ y 33.

Bibliografía: inédita.

Inventario: TM98/CPO/2088 (Fig. 13, nº 9). Procedencia: excavación, UE. 1069.

Cronología del estrato: $2^{\mathrm{a}}$ mitad s. II d.C. sin llegar al final del mismo.

Descripción: fractura lisa. Pasta beige. Inclusiones de fondo transparentes-brillantes y punteadas blancas y gris-negras. Poros. Engobe marrón. 
Material de datación: TSAA 1 Lamboglia 1b; africana de cocina Lamboglia 9 A.

Bibliografía: inédita.

Inventario: $\mathrm{N}^{\mathrm{o}}$ inv. 1211 (Fig. 13, $\mathrm{n}^{\mathrm{o}} 10$ ). Procedencia: fondos museo.

Descripción: fractura lisa-escalonada, pasta de color beige claro, no se aprecian desgrasantes a simple vista.

Poros. Engobe anaranjado.

Bibliografía: inédita.

Inventario: TM02-FO-4598 (Fig. 13, n 11). Procedencia: excavación, UE. 1675.

Cronología del estrato: 231-300 d.C.

Descripción: fractura lisa-rugosa. Pasta marrón. Inclusiones de fondo transparentes-brillantes. Poros. Engobe marrón-rojizo.

Material de datación: TSAA copa Lamboglia 23.

Bibliografía: inédita.

Inventario: TM01-SB-5815 (Fig. 13, n 12 ). Procedencia: excavación, UE. 2195, patio atarjea.

Cronología del estrato: siglo II d.C.

Descripción: fractura lisa. Pasta de color amarillento. Falta de inclusiones y de macroporosidad. Engobe marrón oscuro.

Material de datación: africana de cocina plato-tapadera Ostia III, 332; TSAA; ánfora grecoitálica.

Bibliografía: inédita.

\section{BusSIÈRE AVI 8E}

Inventario: TM-1112 (2), 67-TM-272, CS. 2705 (Fig. 13, $\left.\mathrm{n}^{\mathrm{o}} 13\right)$. Procedencia: fondos museo.

Descripción: fractura lisa. Pasta de color marrón, inclusiones de fondo transparentes-brillantes y punteadas y pequeñas blancas. Falta de macroporosidad. Engobe marrón.

Bibliografía: inédita.

\section{CONCLUSIONES GENERALES}

El estudio que presentamos en este artículo pretende aportar información, sobre todo estratigráfica y cronológica, de unas piezas que permanecían en su gran mayoría inéditas. Como muchas de las lucernas analizadas proceden de estratos excavados con metodología arqueológica se ha intentado datar el objeto no per se sino en relación con el resto de materiales que conforman la misma unidad o conjunto. Morillo $(2015,345)$ ha apuntado recientemente la necesidad de estudiar y publicar los ejemplares republicanos, mucho menos estudiados que los altoimperiales ya que han atraído en menor medida, por diversos motivos, la atención de los investigadores.

Volviendo al tema que nos ocupa hemos podido observar, tras analizar las gráficas tipológicas presentadas en las figuras 4,5 y 6 , el aumento que experimentan, con respecto a los tipos anteriores, los ejemplares Dressel 2, Dressel 3 y Dressel 4. Éste último está menos representado, posiblemente por la aparición de las lucernas de volutas con las que comparten mercado. Nos referimos, en concreto, al tipo Dressel-Lamboglia 9 A ya que ambos tipos (Dressel 4 y Dressel-Lamboglia 9 A) han sido identificados en las mismas unidades estratigráficas.

El hecho de que las primeras lucernas documentadas en el yacimiento (Ricci B, E, G, H y Dressel 1) estén poco representadas puede deberse a que, tras la destrucción sufrida por el yacimiento con motivo de la Segunda Guerra Púnica, el enclave se abandona. No se han localizado contextos de habitación correspondientes al siglo II a.C. aunque sí materiales muebles, prueba ello de la existencia de frecuentaciones esporádicas (Olcina, Guilabert y Tendero, 2014, 204).

A raíz del estudio de los materiales arqueológicos se aprecia un paulatino aumento de los contactos con Roma, hecho este que se traduce en la llegada de ciertos tipos anfóricos y de vajilla fina de mesa de barniz negro. A finales del primer cuarto del siglo I a.C. se detectan cambios ya que tiene lugar una segunda fase de amurallamiento, este impulso urbanizador de carácter militar continuará durante la primera mitad del siglo I a.C. (Olcina, Guilabert y Tendero, 2014, 205).

La mayor presencia en número de ejemplares lucernarios de los tipos Dressel 2 y Dressel 3, con respecto a los existentes con anterioridad (Ricci B, E, G, $\mathrm{H}$ y Dressel 1) (Fig. 4) y la llegada masiva de las importaciones de terra sigillata itálica y, posteriormente, gálica coinciden plenamente con el impulso urbanístico y con el inicio del trazado viario ya que la mayor concentración de ambos tipos de lucernas se da en el intervalo 40/30 a.C. $-1^{a}$ mitad siglo I d.C., fase esta del inicio del auge y esplendor del municipio.

El arranque del periodo de eclosión constructiva viene marcado por el trazado de las dos calles principales en un momento entre principios de la $2^{\mathrm{a}}$ mitad del siglo I a.C. y la llegada de las primeras sigillatas alrededor del año 30 a.C. (Olcina, 2009, 45). La construcción del primer foro municipal se fecha entre el 30 y el 20 a.C., es posible que hacia el año 26 a.C., con el inicio del gobierno de Augusto. Durante su principado y con anterioridad al 12 a.C. se le concede el estatuto municipal y, a consecuencia de ello, se inicia un programa de urbanización y monumentalización por el cual Lucentum se dota de alcantarillado, edificios de culto y espacios públicos, se trazan nuevas calles que delimitan, a su vez, manzanas y se construyen $t a-$ bernae anexas al foro (Olcina, 2009, 38-52; Olcina, Guilabert y Tendero, 2014, 200-216).

El período de máxima vitalidad y esplendor comprende desde las décadas finales del siglo I a.C. hasta finales de la década de los sesenta del siglo I d.C., periodo este que ahora sólo trataremos tangencialmente y que estudiaremos en profundidad en un futuro, cuando atendamos las lucernas de volutas y de disco. 
Por lo que respecta a los talleres alfareros en los que se produjeron las lucernas localizadas en Lucentum, es difícil en estos momentos proceder a su identificación y localización. No hemos realizado análisis de pastas ni disponemos de un corpus general que reúna las diferentes características de las mismas así como las observaciones microscópicas. Estos análisis ayudarían en la resolución del conocido problema de la obtención de copias por sobremoldeado. Es necesario trabajar en este tema para llegar a identificar talleres, las piezas que en ellos se elaboraban y su difusión. Todo ello hace que desconozcamos dónde se produjeron las lucernas, si en talleres cercanos o si bien procedían de lugares más distantes. En el Tossal de Manises (Lucentum) se registra abundancia de materiales procedentes de otros puntos del Imperio destacando en especial la terra sigillata itálica, tardoitálica y la sigillata gálica. Este hecho estaría relacionado con los productos que se importaban desde Italia y Galia, el vino sobre todo, constituyendo la vajilla fina de mesa y las lucernas el cargamento secundario de las embarcaciones. Pensamos que, acompañando a la vajilla de mesa, pudieron haber llegado también lucernas elaboradas en la península itálica pero esto es únicamente una hipótesis que sería necesario confirmar cuando se avance más en el estudio de la composición mineral de las diferentes producciones. A través de las importaciones arriba referidas podemos inferir que Lucentum entraría ya de forma plena en la órbita comercial romana en tiempos de Augusto. Será a partir del gobierno de VespasianoTito cuando asistamos a la manifestación arqueológica de los primeros signos de desaceleración de la vida urbana de Lucentum ya que se evidencia el abandono de los trabajos de mantenimiento de la alcantarilla que drenaba el foro y la parte superior del yacimiento (García, Olcina y Ramón, 2010, 354-356).

En cuanto a los talleres hispanos en los que se ha documentado la elaboración de lucernas de época republicana o tardorrepublicana tenemos en Corduba una producción de lucernas Ricci G con una cronología que abarca del 135 al 30 a.C. (Moreno, 1991, 193-198). La forma Dressel 2 fue producida en La Cabañeta (El Burgo de Ebro, Zaragoza) ya que se ha localizado un molde que las producía a lo largo del primer cuarto del siglo I a.C. hasta las Guerras Sertorianas en que el yacimiento fue arrasado (Mínguez y Mayayo, 2014, 162-163). El molde inferior que serviría para producir lucernas Dressel 4 ha sido localizado en el yacimiento de El Monastil (Elda) con la firma L.EROS y una cronología del último tercio del siglo I a.C. y el primer tercio del siglo I d.C. (Poveda, 2013, 455-467).

Como yacimiento cercano al Tossal de Manises mencionaremos el Tossal de les Basses donde se documentó la existencia de un horno de época romana que, según los datos publicados, sirvió para producir vasijas (Rosser y Fuentes, 2007, 69) aunque sería preciso contar con un estudio que abordara el tema con mayor profundidad.
Tras el desglose realizado tipo por tipo, un hecho que se puede observar, en líneas generales, es la larga duración de algunas tipologías, lo que puede deberse tanto a intrusiones como a nivelaciones realizadas en época clásica así como a las remociones y expolios sufridos por el yacimiento desde la Antigüedad hasta época contemporánea.

Otro aspecto a comentar es que de la mayoría de los grupos tipológicos no contamos con tantos ejemplares como habría sido preciso para poder establecer una cronología de cada tipo en Lucentum, si exceptuamos las formas Dressel 2, Dressel 3 y en menor medida Dressel 4. Para ello será necesario seguir ampliando el estudio a medida que vayan realizándose nuevas campañas de excavación.

\author{
Anna García Barrachina \\ Museo Arqueológico de Alicante \\ Plaza Dr. Gómez Ulla, s/n \\ 03013 Alicante \\ agarciab@diputacionalicante.es
}

\section{BIBLIOGRAFÍA}

AA.VV., 2004: Scombraria, la historia oculta bajo el mar. Arqueología submarina en Escombreras, Cartagena, Murcia.

AQUILUÉ, X., CASTANYER, P., SANTOS, M. y TREMOLEDA, J., 2008: «L'evolució dels contextos ceràmics d'Empúries entre els segles II a.C. i VII d.C.», Actes $d u$ Congrès de la SFÉCAG tenu à L'Escala-Empúries du ler au 4 mai 2008, 33-62, Marseille.

ARXÉ, J., 1982: Les llànties tardo-republicanes d'Empúries, Barcelona.

BERGES, G., 1989: Les lamps de Montans (Tarn). Une production céramique des Ier et IIe s. ap. J.-C.: modes de fabrication, typologie et chronologie, Paris.

BUSSIÈRE, J., 1995: «Lampes hellénistiques et tardo-républicaines. Lampes d'Algérie II», Antiquités Africaines, 31, 232-276.

CASAS, J. y ROCAS, X., 1989: «Les llànties de la vil·la romana dels Tolegassos. Algunes precisions entorn la seua datació», Cypsela, VII, 71-86.

CELIS, R., 2008: Les llànties romanes de Baetulo, Tesi doctoral defensada el 9 de juny de 2008. http://raulcelis.net/ (Consulta: 25-3-2012).

DÍAZ, M., 2000: «Tipocronología de los contextos cerámicos tardo-republicanos en Tarraco», Empúries, 52, 201-260.

DRESSEL, H., 1899: Lucernae Formae, C.I.L. (Inscriptiones Urbis Romae Latinae. Instrumentum domesticum) XV, II, 1, lám. III.

GARCIA, A.M., OLCINA, M. y RAMÓN, J.J., 2010: «Un nivel de amortización de una cloaca de Lucentum», Rei Cretariae Romanae Fautorum Acta, 41, 353-361.

GUILABERT, A., MOLTÓ, F.J., OLCINA, M. y TENDERO, E., 2010: «El foro altoimperial de Lucentum. Contextos materiales de su fundación», en V. Revilla i M. Roca (eds.), Contextos ceràmics i cultura material 
d'època augustal a l'occident romà, Actes de la reunió celebrada a la Universitat de Barcelona els dies 15 i 16 d'abril de 2007, Barcelona.

HARTLEY, B. R. y DICKINSON, B. M., 2008: Names on terra sigillata. An index of makers'stamps and signatures on gallo-roman terra sigillata (samian Ware), Vol. I (A to Axo), London.

LÓPEZ, A., HUGUET, E. y RIBERA, A, 2013: «Las otras cerámicas finas», en A. Ribera (coord.), Manual de cerámica romana. Del mundo Helenístico al Imperio Romano, 207-213, Alcalá de Henares.

LAFUENTE, J., 1957: Alicante en la Edad Antigua, Alicante.

LAFUENTE, J., 1959: Museo Arqueológico Provincial de Alicante. Catálogo-guía, Alicante.

LERMA, J.V., 1988: «Lucernas romanas de Valentia», Revista de Arqueología, 85, 29-35.

MARTÍN, G., 1962: «Estudio de los materiales arqueológicos hallados en el subsuelo del Palacio de la Generalidad de Valencia», Papeles del Laboratorio de Arqueología, 1, 89-109.

MARTIN, A., 2008: «Àmfores tarraconenses i bètiques en els derelictes de mitjan segle I a.C. a la costa catalana», Actes du Congrès de la SFÉCAG tenu à L'Escala-Empúries du 1er au 4 mai 2008, 103-127, Marseille.

MÍNGUEZ, J.A. y MAYAYO, A., 2014: «Evidencias de la fabricación de lucernas en la ciudad romanorrepublicana de La Cabañeta (El Burgo de Ebro, Zaragoza», en R. Morais, A. Fernández e M.J. Sousa (eds.), As produçoes cerâmicas de imitaçao na Hispania, tomo I, 151-164, Porto.

MORENO, F., 1991: Lucernas romanas de la Bética, Madrid.

MORILlO, A., 1992: Cerámica romana de Herrera de Pisuerga (Palencia, España). Las lucernas, Santiago de Chile.

MORILLO, A., 1996: «Las lucernas del tipo de «cabeza de ave» (Vogelkopflampen) en la Península Ibérica», $M a-$ drider Mitteilungen, 37, 103-120.

MORILLO, A., 1999: Lucernas romanas en la región septentrional de la península ibérica. Contribución al conocimiento de la implantación romana en Hispania, Montagnac.

MORILLO, A., 2015: «Lucernas romanas en Hispania: entre lo utilitario y lo simbólico», Manual de cerámica romana II. Cerámicas romanas de época altoimperial en
Hispania. Importación y producción, 321-428, Alcalá de Henares.

NOLLA, J.M., 1999: «El material ceràmic dels nivells fundacionals de Gerunda. Els estrats inferiors de casa Pastors», Revista d'Arqueologia de Ponent, 9, 181-214.

OLCINA, M., REGINARD, H. y SÁNCHEZ, Mª J., 1990: Tossal de Manises (Albufereta, Alicante). Fondos antiguos: lucernas y sigillatas, Alicante.

OLCINA, M. (ed.), 2009: Lucentum (Tossal de Manises, Alicante). Arqueología e Historia, Alicante.

OLCINA, M., GUILABERT, A. y TENDERO, E., 2014: «El municipi de Lucentum», en M. Olcina (ed.), Ciudades Romanas Valencianas/Ciutats Romanes Valencianes, Actas de las Jornadas sobre Ciudades Romanas Valencianas. Actualidad de la investigación históricoarqueológica, celebradas en el MARQ (Alicante) los días 3 y 4 de diciembre de 2013, 200-216, Alicante.

PAVOLINI, C., 1987: «Le lucerne romana fra il III sec. aC e il III sec. dC», Céramiques hellénistiques et romaines, 2, 139-165, Paris.

POVEDA, A.M., 2012: «La producción de lucernas en el sureste peninsular: primeros datos», en D. Bernal, y A. Ribera (eds.), Cerámicas hispanorromanas II. Producciones regionales, 353-367, Cádiz.

POVEDA, A.M., 2013: «La officina de lucernas romanas de Elo (El Monastil, Elda, Alicante) en los siglos I a.C./I d.C.», Monografias ex officina hispana 1, tomo I, 455467, Cádiz.

RIBERA, A. y MARÍN, C., 2004-05: «Las cerámicas del nivel de destrucción de Valentia (75 a.C.) y el final de Azaila», Kalathos, 22-23, 271-300.

RICCI, M., 1973: «Per una cronologia delle lucerne tardorepubblicane», Rivista di Studi Liguri, XXXIX, 2-4, 168-234.

RICKMAN, C. y WYNICK, N., 1994: Cosa: the lamps, Memoirs of the American Academy in Rome, volume XXXIX, Michigan.

RIVET, L., 2008: «Les ensembles céramiques d'époque augustéenne de la butte Saint-Antoine à Fréjus (Var). Recherches dans la cour secondaire LX (1973-1976)», Actes du Congrès de la SFÉCAG tenu à L'Escala-Empúries du ler au 4 mai 2008, 765-802, Marseille.

ROMERO, Mª V., 1990: «Lucernas republicanas de Numancia y sus campamentos», Boletín del Seminario de Estudios de Arte y Arqueología, 56, 257-296.

ROSSER, P. y FUENTES, C. (coords.), (2007): Tossal de les Basses. Seis mil años de historia de Alicante, Alicante.

Recepción: 27-05-2016

Aceptación: 20-09-2016 